\title{
DETAILED DAMAGE CHARACTERISTICS IN A
}

\section{CAVITATING VENTURI}

M. J. Robinson

F. G. Hammitt

Laboratory for Fluid Flow and Heat Transport Phenomena Nuclear Engineering Department

The University of Michigan

Interna1 Report No. 30

(Summarization of TR 16 and 17 for Presentation as

a Technical Paper)

June, 1966 


\section{ABSTRACT}

Detailed observations of cavitation pitting and the accompanying flow regime in cavitating venturis using water and mercury have been made. From these it is tentatively concluded that microjet impingement is the most important damaging mechanism for this type of flow, which is generally typical of much fluid flow machinery.

Effects of grain size on damage rate are measured as is the surface-hardening due to cavitation attack.

Correlations of limited generality are presented between accumulated damage and material mechanical properties, leading to the tentative conclusion that no such general correlation is possible. 
ACKNOWLEDGMENTS

The authors would like to thank Professor C. A. Siebert of the Chemical and Metallurgical Engineering Department, The University of Michigan, for his assistance and advice throughout this work.

Financial support was provided by NASA Grant No. NsG-3960. 
TABLE OF CONTENTS

Page

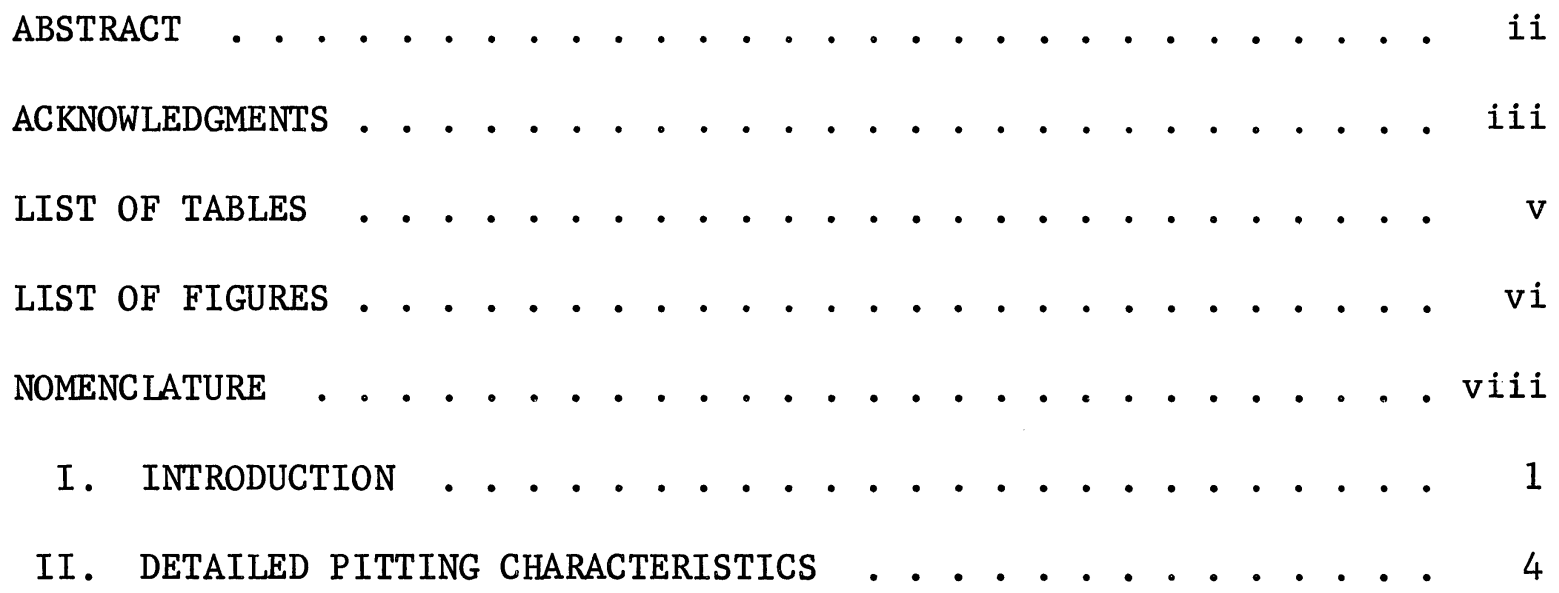
A. General
B. Comparison of Cavitation and Droplet Impact Pitting
C. Pit Contours as Affected by Liquid Throat Velocity

III. PIT AND BUBBLE SIZE AND LOCATION SPECTRA . . . . . . . .
A. Genera1
B. High-Speed Bubble Pictures
C. Liquid Contact-Time Measurements
D. Static Pressure Measurements
E. Pit Size and Location Distribution
F. Bubble Population Vs. Pitting Rate
G. Energy Considerations
H. Implications for Damaging Mechanisms

IV. DAMAGE RATES AS FUNCTION OF FLUID AND MATERIAL PROPERTIES • •
A. Genera1
B. Mercury Vs. Water
C. Effects of Grain Shape and Size
D. Cavitation Surface Hardening
E. Correlations of Damage Rate with Mechanical Properties

V. CONCLUSIONS . . . . . . . . . . . . . . . 46

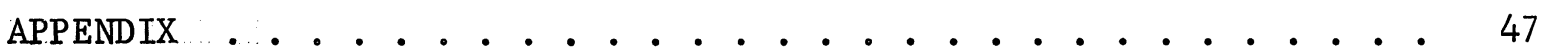
BIBLIOGRAPHY . . . . . . . . . . . . . . . . . 49 


\section{LIST OF TABLES}

Table

Page

1. Mechanical Properties of Materials Used . . . . . . . 28

2. Single Property Correlations for the Mercury Tests . . . . 43

3. Single Property Correlations for the Water Tests . . . . 44

4. Best Multiple Property Correlations for both the Mercury and Water Tests . . . . . . . . . . . . 45 
LIST OF FIGURES

1. Sequence of Toroida1 Bubble Collapse in Water from TwoDimensional Venturi Tests . . . . . . . . . . 3

2. Schematic of $1 / 2^{\prime \prime}$ Plexiglas Damage Venturis ....... 5

3. Photograph and Schematic of Damage Test Specimens ..... 6

4. Comparison of Jet Impact Craters to Cavitation Craters - . 8

5. Typical Proficorder Trace and Corresponding Photomicrograph of Cavitation Damage Pits on 304 SS in Mercury

Facility ..................

6. Directional Variation of Cavitation Damage Pits Versus

Venturi Test Velocity in Water . . . . . . . . .

7. Typica1 Proficorder Trace and Corresponding Photomicrograph of Cavitation Damage Pits on SS in Water . . . . . .

8. Photograph of Transparent Photographic Specimen-Holder

Combination . . . . . . . . . . . . . . .

9. Typical Sequence of Pictures of Cavitating Flow on Specimen Surface for Standard Cavitation in Mercury . . . . . . . 18

10. Photograph of Electrode Specimen-Holder Combination . . .

11. Percent Contact Time of Mercury to Surface from Electrode Specimen-Holder Measurements . . . . . . . .

12. Normalized Pressure Profile for Throat Velocity of 33.1 $\mathrm{ft} . / \mathrm{sec}$. and "Standard Cavitation" in a $1 / 2$ " Venturi with Mercury ..................

13. Pit Size Spectrum for Downstream Position on Specimen Surface for $\mathrm{SS}$ in $\mathrm{H}_{2} \mathrm{O}$ and $\mathrm{SS}, \mathrm{CS}, \mathrm{Cb}-1 \mathrm{Zr}$ in Mercury ...

14. Pit Size Spectrum Versus Distance Along Test Specimen Surface for $\mathrm{Cb}-1 \mathrm{Zr}$ in Mercury . . . . . . . . .

15. Comparison of Number of Bubbles, Number of Pits, and $p-p_{v}$ Per Unit Time Versus Axial Distance Along Test Specimen Polished Surface in Mercury . . . . . . . . . .

16. Ratio of Number of Bubbles Per Second to Number of Pits Per Second on SS and $\mathrm{Cb}-1 \mathrm{Zr}$ in Mercury ......... 
17. Ratio of Calculated Total Available Bubble Collapse Energy to Surface Distortion Energy Versus Pressure Above Vapor Pressure .....................

18. Ratio of Calculated Energy Per Single Bubble Collapse to Surface Distortion Energy for a Single Pit Versus Pressure Above Vapor Pressure . . . . . . . . . . 34

19. Cavitation Damage on Copper-Zinc-Nickel Alloys Versus Grain Size for Selected Ranges of Mechanical Properties . . . 38

20. Microhardness Versus Axial Distance on Cavitated Copper Specimens at Selected Test Durations . . . . . . . . 39

21. Microhardness Versus Axial Distance on Cavitated Brass at Selected Test Durations . . . . . . . . . . . . . 
NOMENCLATURE

Symbo1 Description

AcI

Acoustic Impedance Ratio of Material and Fluid $=$

$$
\frac{\left(\rho(E / \rho)^{1 / 2}\right) \text { fluid }}{\left(\rho(\mathrm{E} / \rho)^{1 / 2}\right) \text { material }}
$$

As Rec'd As Received Material Condition $=60 \%$ Cold-Worked

BHN Brine11 Hardness Number, $500 \mathrm{Kg}$ Load

CS Carbon Stee1

$\mathrm{Cb}-1 \mathrm{Zr} \quad$ Columbium-1\% Zirconium Alloy

DPH Diamond Pyramid Hardness

ESE Engineering Strain Energy

E Elastic Modulus

H.H.Trt. High Heat Treat, Highest Temperature Anneal for Copper, Zinc, Nicke1 Alloys

L.H.Trt. Low Heat Treat, Lowest Temperature Anneal for Copper, Zinc, Nickel Alloys

MDP Mean Depth of Penetration, Total Weight Loss Divided by Material Density per Unit Area

p Pressure, $1 \mathrm{bf} /$ inch $^{2}$

$\mathrm{p}_{\mathrm{V}} \quad$ Vapor Pressure

ppm Parts per Million

$\% 1 \quad$ Percent Elongation

$\%$ Percent Reduction of Area

SS $\quad$ Stainless Stee1

TBS True Breaking Stress

TSE True Strain Energy

TS Tensile Strength

YS Yield Strength 


\section{DETAILED DAMAGE CHARACTERISTICS IN A CAVITATING VENTURI}

\section{INTRODUCTION}

Damage to structural materials by cavitation, often assisted materially by conventional erosion and corrosion, has long been a serious problem to the manufacturers and users of fluid-handling equipment. In the past it has been possible to avoid the problem to some extent by over-conservative design. However, in many present-day applications, such as in the aerospace fields, this may no longer be a feasible alternative. Hence, it becomes more and more important to understand the fundamentals of the cavitation damage processes so that realistic predictions of damage to be encountered in a wide variety of machines, materials, fluids, temperatures, velocities, etc., can be made. Also, if the damaging processes are more clearly understood it may be possible to devise methods of inhibiting damage in a given situation by suitable fluid additives, material choice, surface treatment, prestressing, coatings, etc.

The present paper concerns detailed observations on cavitation damage incurred by a variety of materials which are chemically compatible with the fluid, in water and mercury in a cavitating venturi, and also on the flow regime to which they were exposed. From these observations, several indications shedding important light on the actual damaging mechanisms are evident. The trend of this evidence strengthens the belief that the observed damage results primarily from a high-velocity 
microjet of liquid originating from the toroidal collapse of individual cavitation bubbles. This possibility has been discussed by previous investigators, perhaps starting with Kornfeld and Suverov. ${ }^{1}$ Such collapses of hemispherical bubbles formed in contact with a plane surface by spark electrodes in a static system, and the resulting stress field below the jet on a photoelastic material, were later observed by Naude and Ellis. $^{2}$ Somewhat similar pictures from a similar set-up were later obtained by Shutler and Mesler. ${ }^{3}$ However, the resulting pitting on their soft metal target materials was below the torus rather than the central jet. This investigation ${ }^{3}$ did confirm the existence of the toroidal collapse in that configuration. Still more recently, toroidal collapses were pictured for bubbles rising in a static beaker by Benjamin and Ellis ${ }^{4}$ and also Florschuetz and $\mathrm{Chao}^{5}$ and in a cavitating venturi diffuser by Ivany, Hammitt and Mitche $11^{6}$ in this laboratory. The latter investigation, ${ }^{6}$ in which all collapses in the strong pressure gradient of the venturi diffuser appeared to be of the toroidal type, convinces us that this type of collapse is probably typical in most flowing cavitating situations, where strong pressure gradients usually do exist. However, since the axis for the toroidal collapses in the venturi (Figure 1) were parallel to the venturi axis, with the jet oriented in the upstream direction, it is not clear how damage to the surrounding structure results. The present paper investigates this situation from the viewpoint of the pitting characteristics, population, and size distribution, as compared with similar data for the bubble population adjacent to the damaged specimens rather than from detailed photos of bubble collapse. 

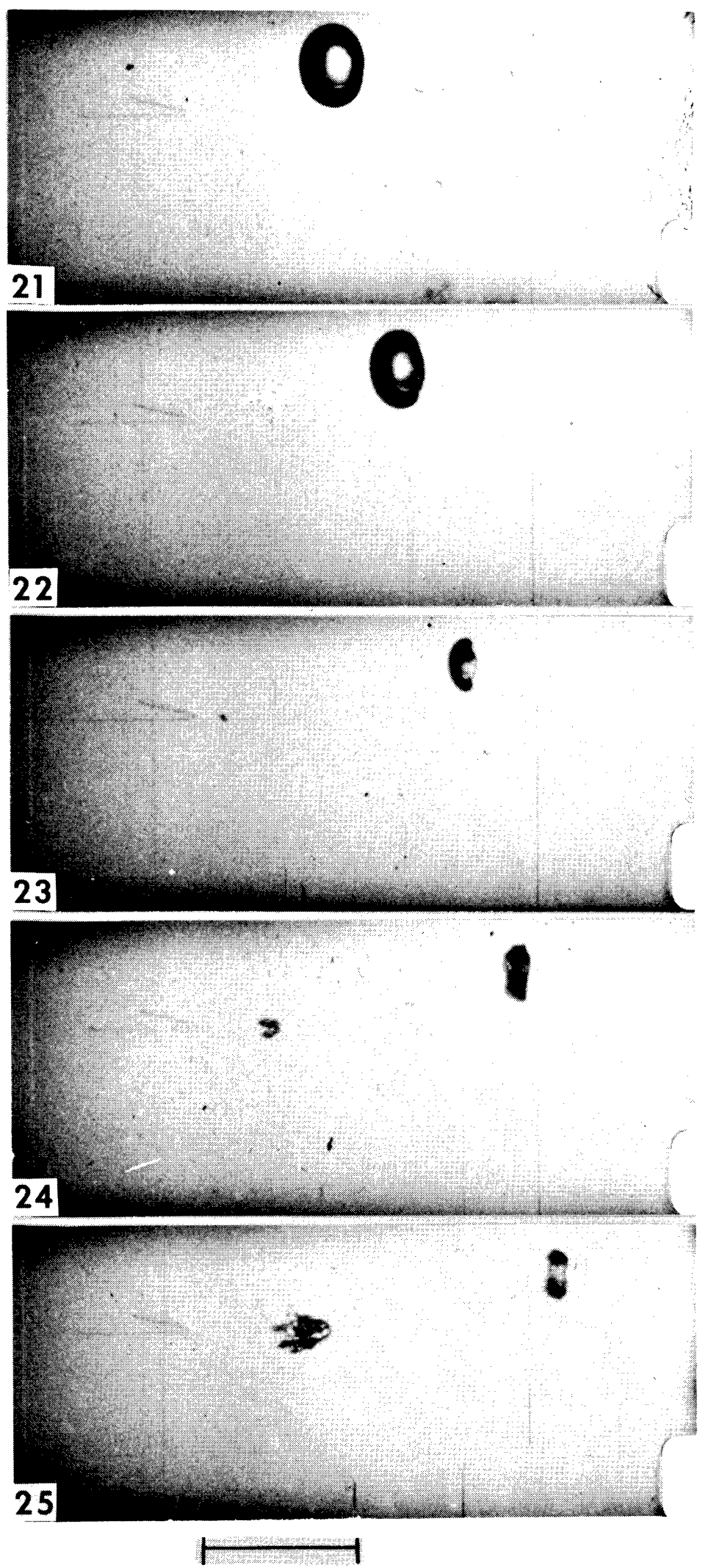

Fig. 1.--High-speed photographs of bubble collapse in twodimensional venturi with $1 / 4^{\prime \prime}$ throat in water at $74.6 \mathrm{ft} . / \mathrm{sec}$. Air content $2.35 \%$ by volume, 132 microseconds between frames, 1 microsecond exposure, flow left to right, scale length 0.25 inches. 
The likelihood of the microjet damage mechanism vs. the classical Rayleigh shock wave mechanism is increased by the results of two recent numerical analyses of bubble collapse using real fluid properties. $^{7,8}$ Both showed that pressures during a spherical collapse were not sufficient to cause the observed damage, assuming the bubble collapse center to remain stationary during the collapse. It is possible that movement of the collapse center toward the surface, which exists theoretically, is sufficient to invalidate the above result; or alternatively that the damage is done only by rebounding bubbles, from which the pressures are considerably greater. ${ }^{7,8}$ However, the possibility of a spherically symmetrical collapse so near a boundary is poor and any departure from symmetry should reduce the shock-wave intensity.

Detailed characteristics of the damage and its relation to material mechanical properties are also presented.

\section{DETAILED PITTING CHARACTERISTICS}

A. Genera1. Many details of the pitting of damage specimens in cavitating venturis in this laboratory and descriptions of the facility have been reported. ${ }^{9,10,11}$ For convenience, the basic venturi designs are shown in Figure 2. They differ only in material of construction (plexiglas or stainless steel) and the geometry of damage specimen insertion: one, two (at $120^{\circ}$ or $180^{\circ}$ ), or three specimens (spaced symmetrica1ly). Figure 3 shows the test specimen design. "Cavitation condition" refers to the visually determined extent of the cavitating zone. These are defined in the appendix. The present paper discusses new 

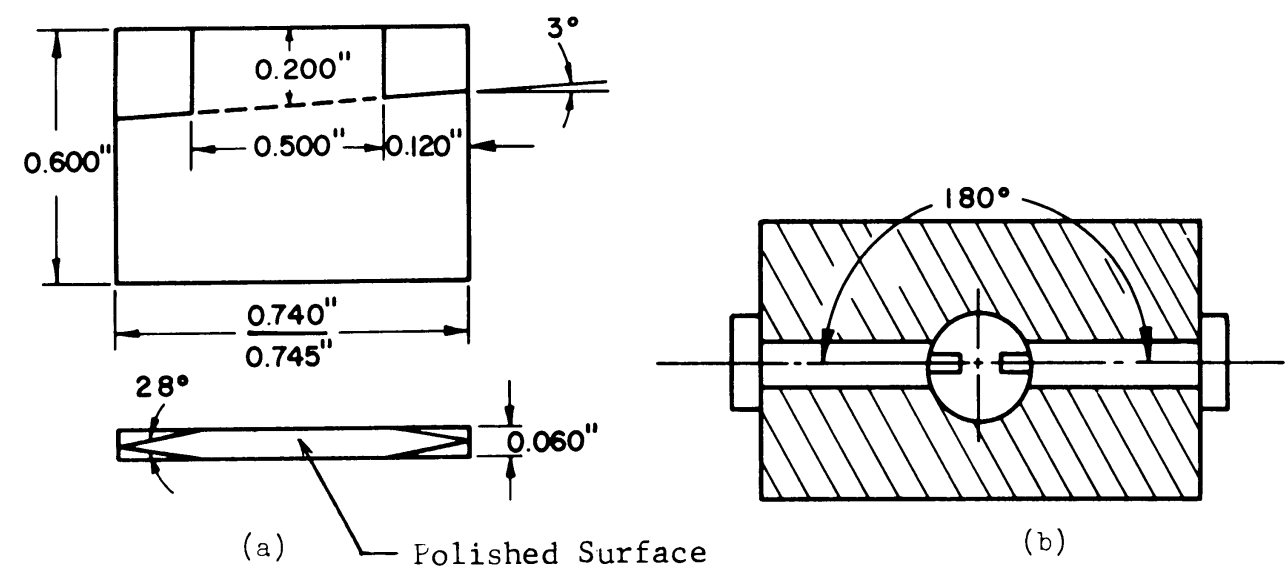

(b)
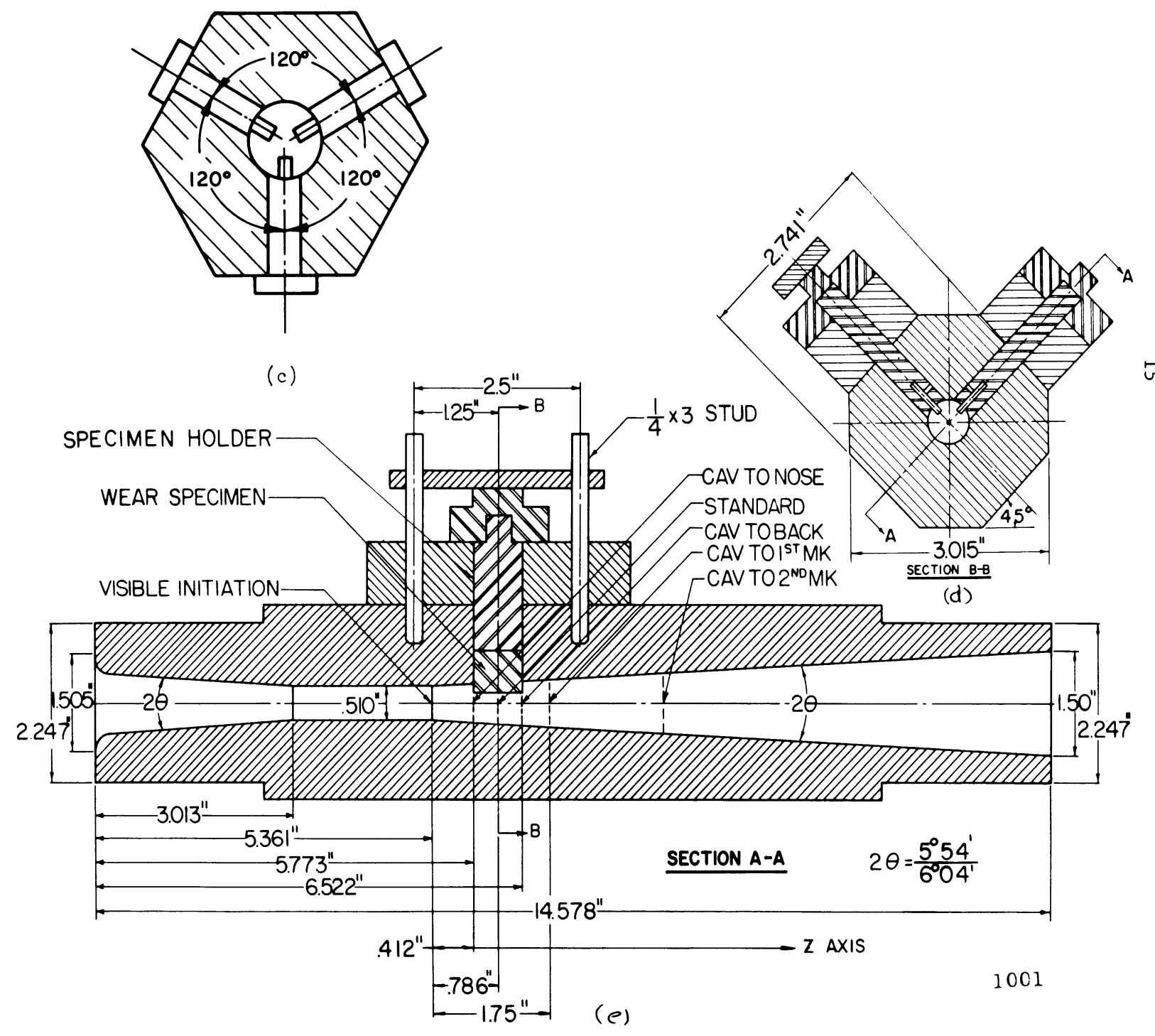

Fig. 2.--Schematic drawing of the damage test venturis showing nominal flow passage, axial specimen location, cavitation termination points, and (a) test specimen dimensions, (b) two specimen symmetrical arrangement for mercury, (c) three specimen symmetrical arrangement for water, (d) two specimen unsymmetrical arrangement for earlier mercury tests, (e) damage venturi. 

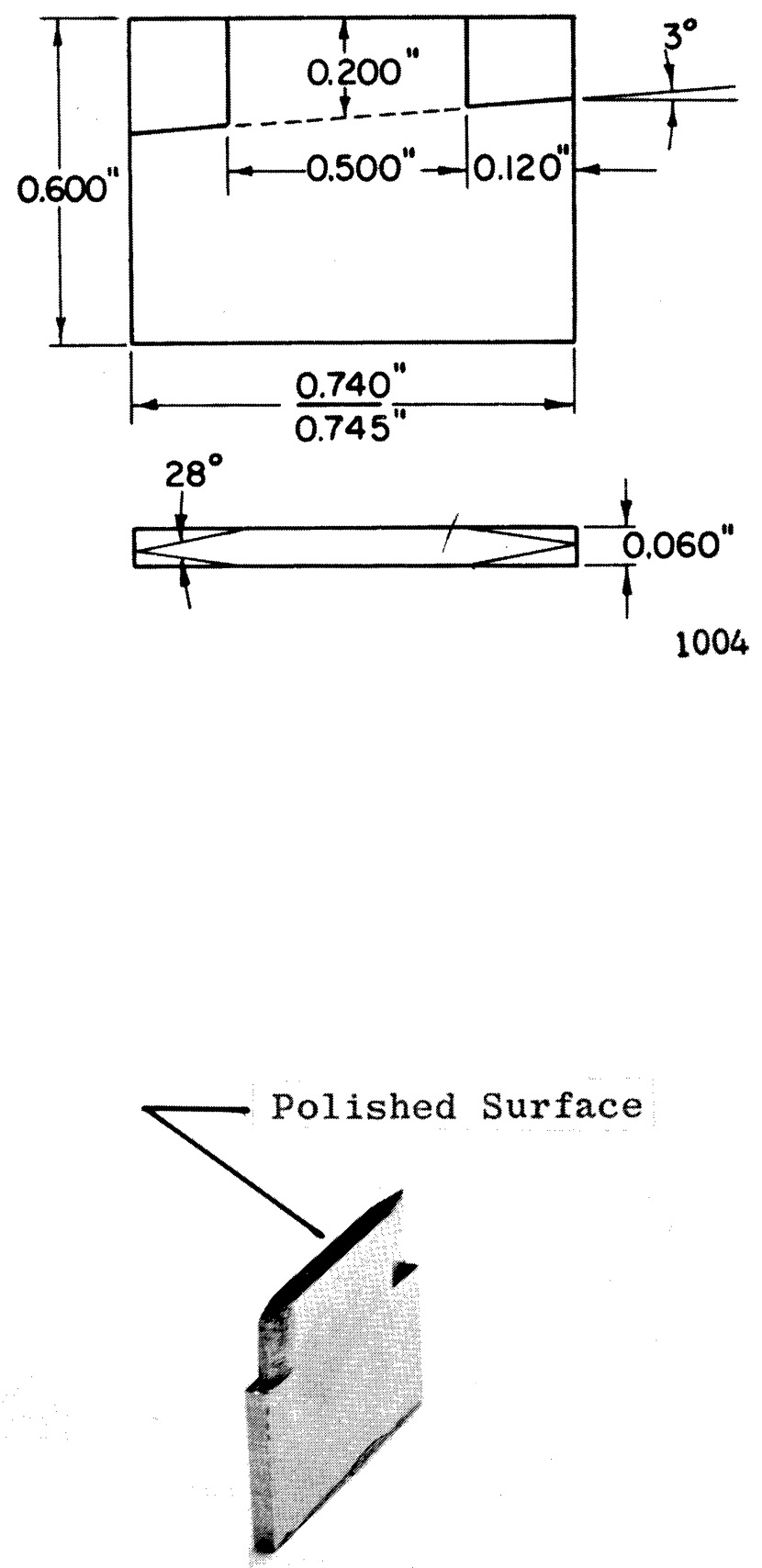

1005

Fig. 3.--Schematic drawing and photograph of damage specimen 
detailed observations $^{12}$ of the pitting which are thought relevant to improved understanding of the basic damage mechanisms.

B. Comparison of Cavitation and Droplet Impact Pitting. It has long been realized that droplet or jet impact pitting is very similar in appearance to cavitation pitting. Thus jet impact machines have been used in the past for testing the "cavitation resistance" of materials. 13 , 14,e.g. This similarity is not surprising if cavitation damage is in fact caused by microjet impact.

In the present study many proficorder ${ }^{*}$ traces of cavitation pits on various materials cavitated in both water and mercury have been made along with large magnification photomicrographs of the same pits, so that a precise identification of the pits traced can be made. ${ }^{12}$ When these are compared with pits in a similar material ${ }^{15,16}$ (Figure 4) the profiles are closely similar. It is thus possible to infer, from the impact velocities used, ${ }^{15,16}$ that the cavitation microjet velocity (if such exists) is approximately $600 \mathrm{ft} . / \mathrm{sec}$. for mercury and approximately $4000 \mathrm{ft} . / \mathrm{sec}$. for the water tests. Also the microjet diameter is estimated by comparison with the jet impact tests of DeCorso ${ }^{15}$ to be about one-quarter of the pit diameter. Thus the cavitation microjet diameters must range from a few hundredths of a mil up to a mil. Comparison with droplet impact tests by Enge $1^{18}$ show that the drop diameter is about equal to pit diameter for the range of velocity comparable to the cavitation case. Thus the jet and drop may well have the same mass. That the jet velocities producing pits similar to the cavitation pits of the

*Manufactured by Micrometrical Incorporated, Division of Bendix Corp., Ann Arbor, Michigan. 


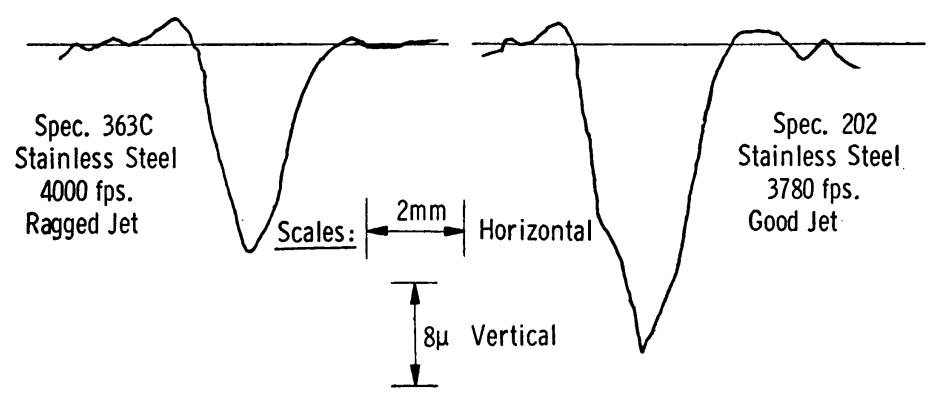

a) Water impact pit profiles from DeCorso.
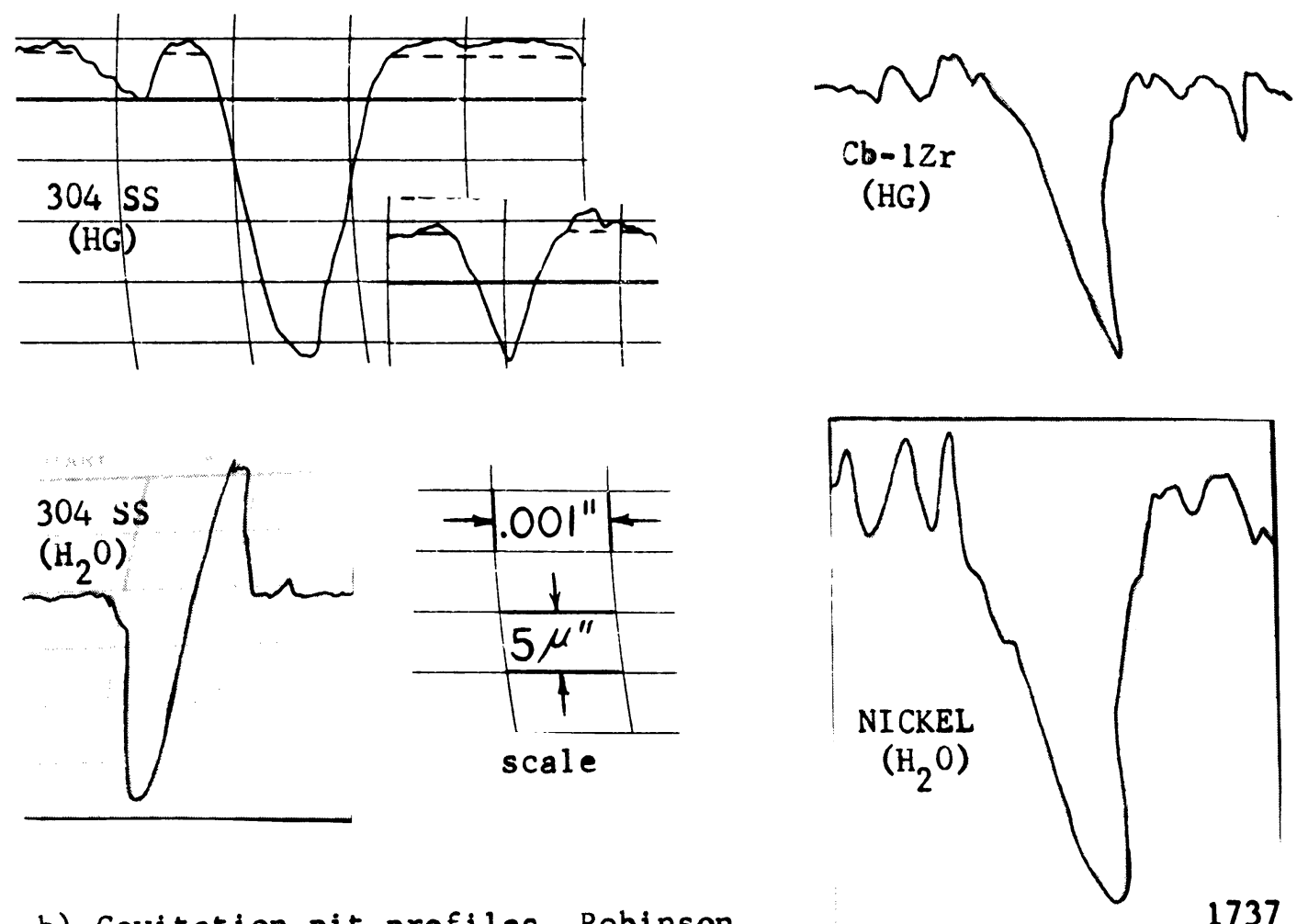

b) Cavitation pit profiles, Robinson .

Fig. 4.--Comparison of high velocity water jet impact craters and cavitation damage craters. 
present tests are greater for water than for mercury is expected since the flow velocities employed in the water cavitation tests are greater than those used for mercury. Since the geometrical configurations and the "cavitation conditions" are the same, all system velocities, as a first approximation, would be roughly proportional.

In the present cavitation tests, the diameter-to-depth ratios of the pits are large, ranging typically from about 10 to about 50 . This is typical for droplet-impact pits in the velocity range indicated on the test materials for which a comparison between cavitation and impact pitting is available. However, it has been noted from impact tests 16 of mercury on copper (from which the estimate of $600 \mathrm{ft} . / \mathrm{sec}$. jet velocity was obtained) that for decreasing impact velocity the diameter-to-depth ratio increases. Presumably, this is also true for fixed droplet velocity if target strength properties are decreased. A comparison of single-blow cavitation craters from a $1400^{\circ} \mathrm{F}$ pump test on a stainless steel impeller in potassium ${ }^{17}$ with either the present cavitation pits, or pits produced by relatively high-velocity droplet impact upon soft materials, ${ }^{18}$ indicates the same trend. The craters from the $1400^{\circ} \mathrm{F}$ pump test or the impact tests on soft materials are proportionally very deep compared with those from our own low temperature cavitation tests on stainless steel (where the material strength is much greater than, and the applicable fluid properties and flow conditions roughly similar to, the $1400^{\circ} \mathrm{F}$ potassium test). Thus the same trend of variation of crater diameter-to-depth ratio for differing material properties exists for both droplet impact and cavitation cratering. 
C. Pit Contours as Affected by Liquid Throat Velocity. The present tests cover a range of throat velocity from about $20 \mathrm{ft} . / \mathrm{sec}$. in mercury to about $200 \mathrm{ft} . / \mathrm{sec}$. in water, all in venturis with the same flow path (Figure 1). Over this range, the pits differ from approximately symmetrical craters with axis perpendicular to the specimen surface to "trenches" elongated in the direction of flow. While the ridges about the craters are roughly symmetrical at the lowest velocity, they are concentrated about the downstream end and sides of the pit for the higher velocities. ${ }^{9,12}$ Figure 5 shows typical photomicrographs with accompanying proficorder traces from low velocity mercury tests. A majority of the pits are roughly circular craters. An examination of these and other proficorder traces ${ }^{12}$ shows the ridges are approximately symmetrical about the pit centerline, as are the pits.

Figure 6 shows pits from water tests on copper-nicke1 alloy at three velocities: 65, 97, and $199 \mathrm{ft} . / \mathrm{sec}$. As the velocity is increased, the pit shape alters from roughly circular to triangular wedges and finally to the elongated trenches previously described. Figure 7 shows similar pits with accompanying proficorder traces for stainless steel in water at $200 \mathrm{ft} . / \mathrm{sec}$. Examination of these and other traces obtained for this condition ${ }^{12}$ shows that the ridge is predominantly on the downstream edge. Thus the high velocity pits are "tipped," with axis pointing somewhat upstream of the perpendicular direction.

Elongated pits of this type were observed earlier. ${ }^{10}$ It was thought that their shape might result from the direction in which the 


\section{Trace Direction}

Flow
Direction

1

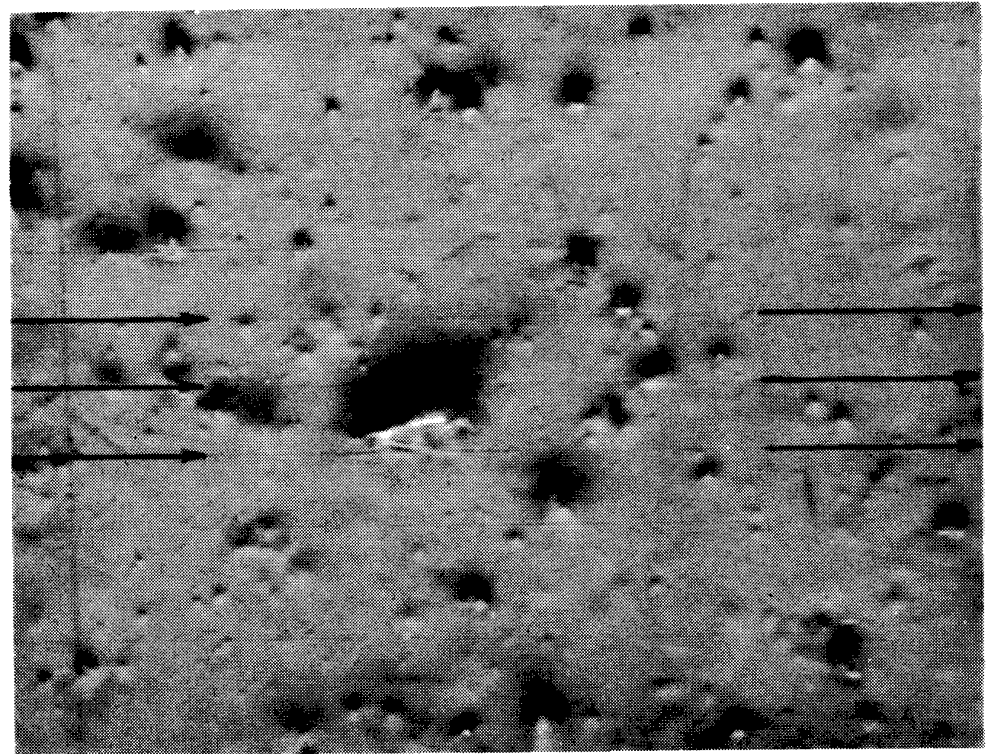

1

$.0079^{\prime \prime}$
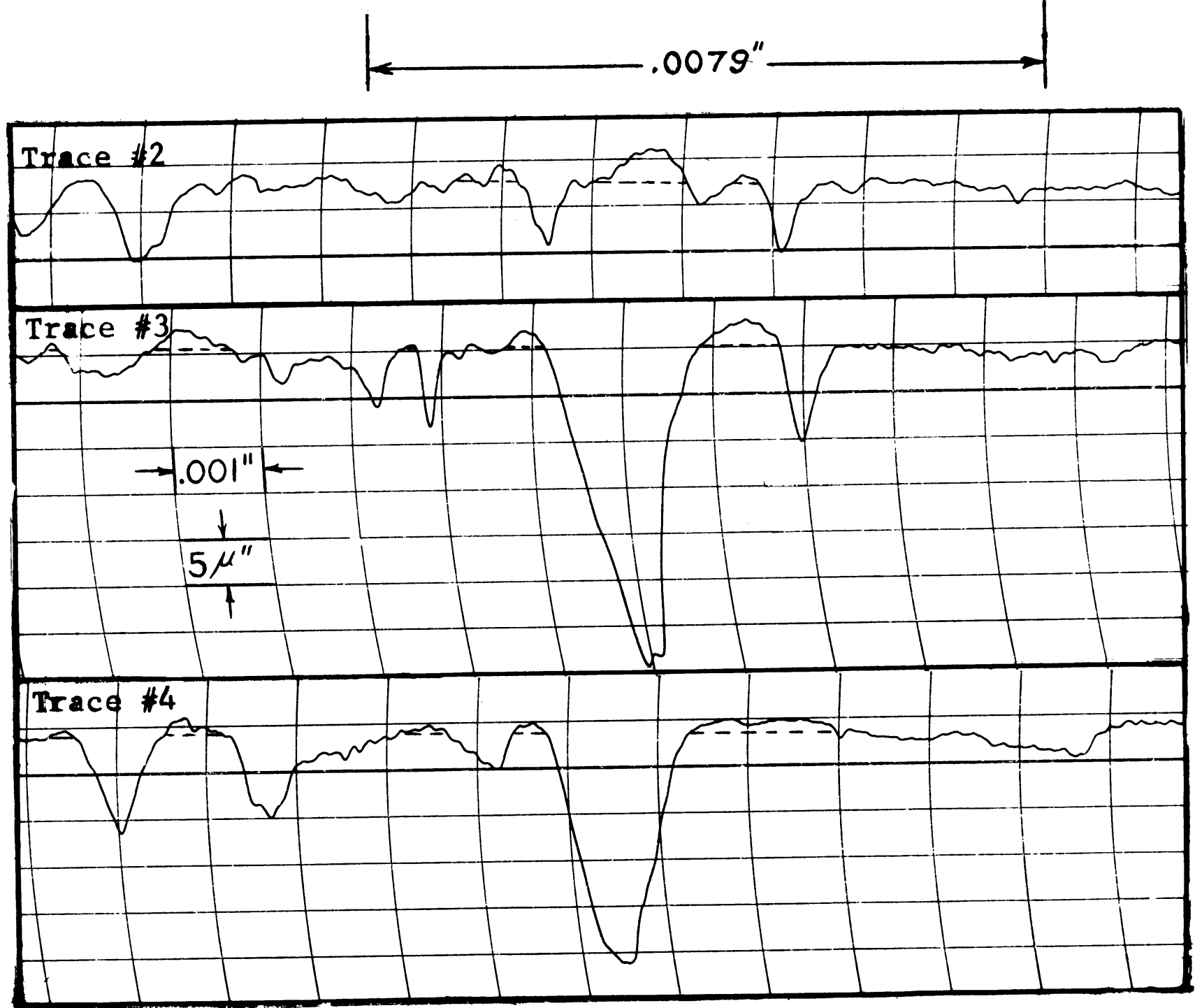

Fig. 5.--Photomicrograph and corresponding proficorder traces of surface of specimen 22-SS (304 stainless stee1), after 10 hours exposure to "standard cavitation" in mercury at a throat velocity of 34 feet per second. 

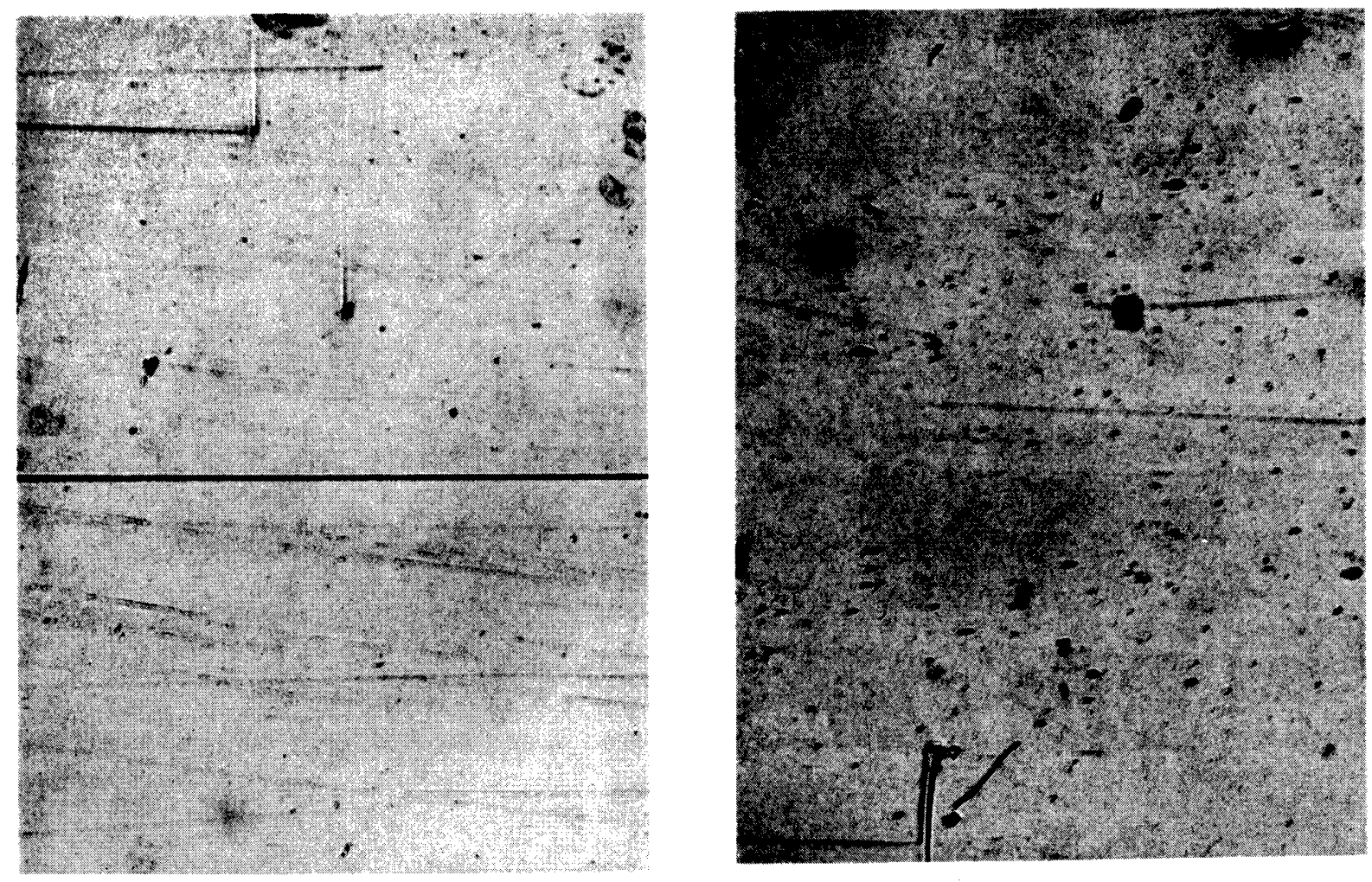

(a)

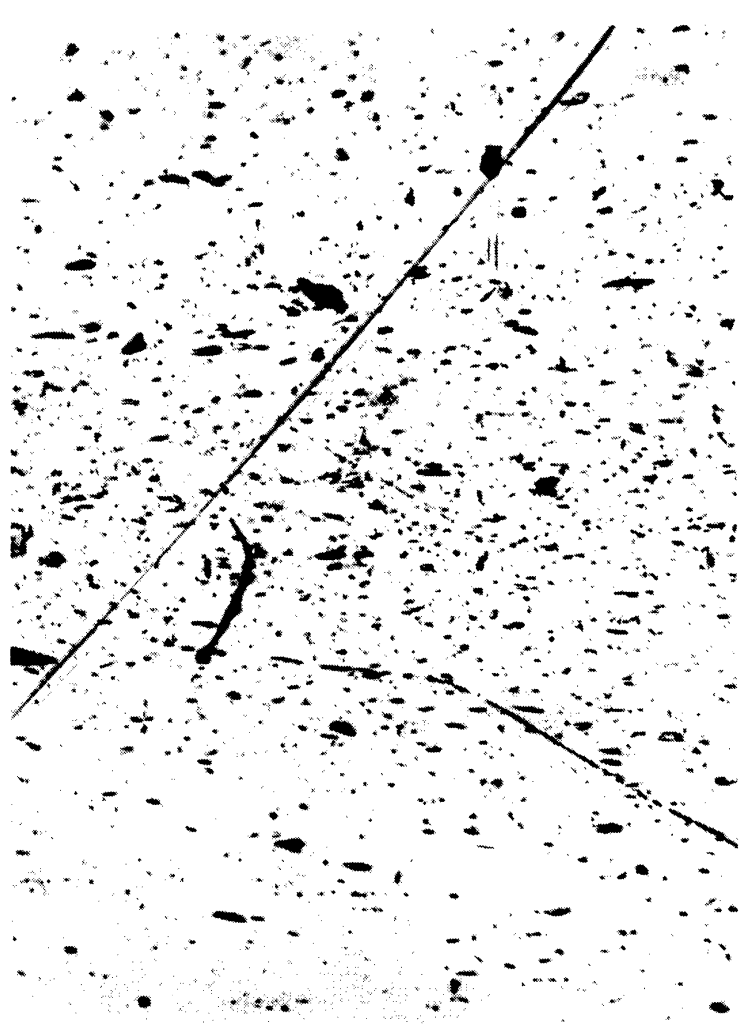

(b)

(c)

Fig. 6.--Photomicrographs of cavitation damage on copper-nicke1 alloy (H.H.Trt), for "standard cavitation" in water at one hour duration, (a) $65 \mathrm{ft} . / \mathrm{sec}$. , (b) $97 \mathrm{ft} . / \mathrm{sec} .$, (c) $199 \mathrm{ft} . / \mathrm{sec}$. 

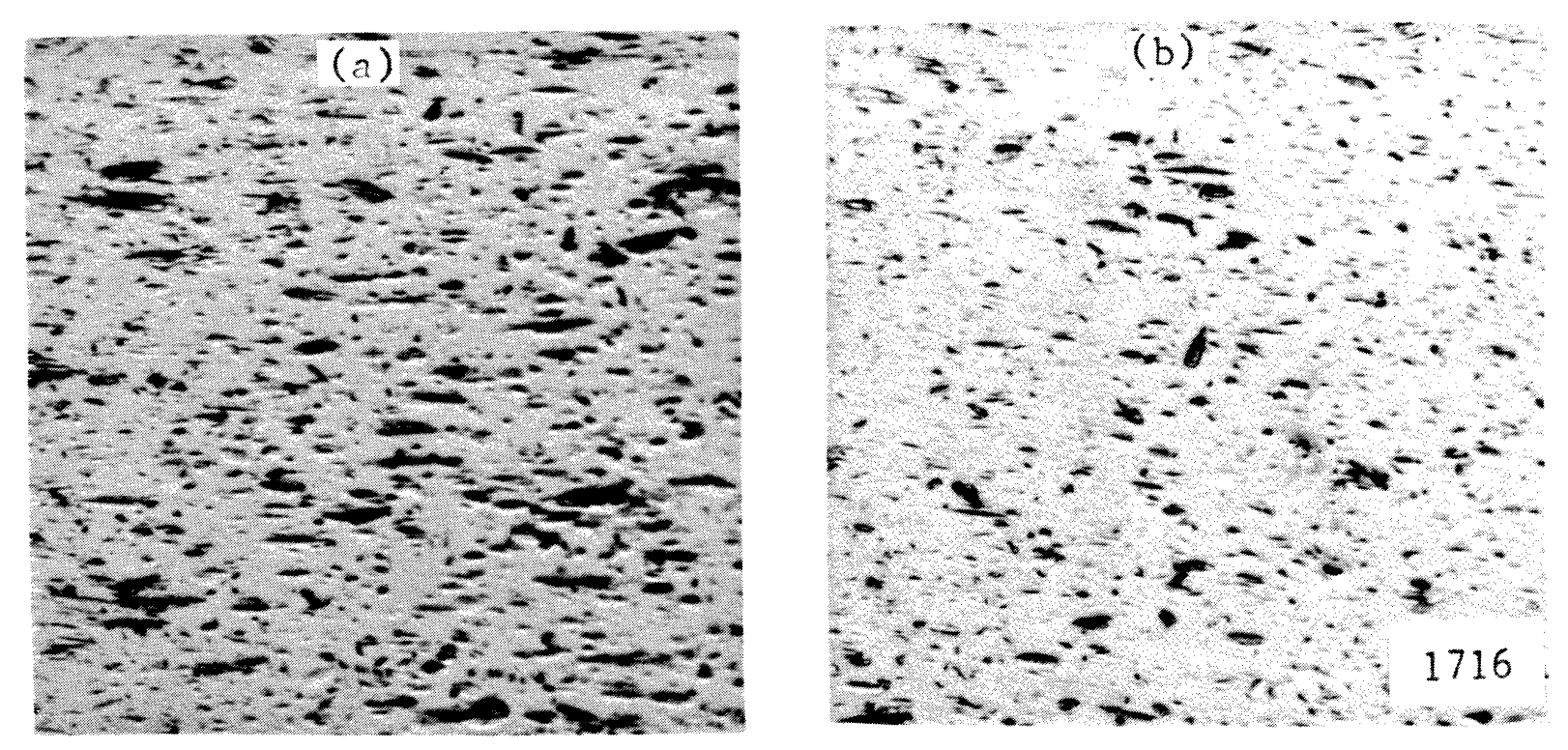

Flow Direction $\longrightarrow$

Trace Direction $\longrightarrow$

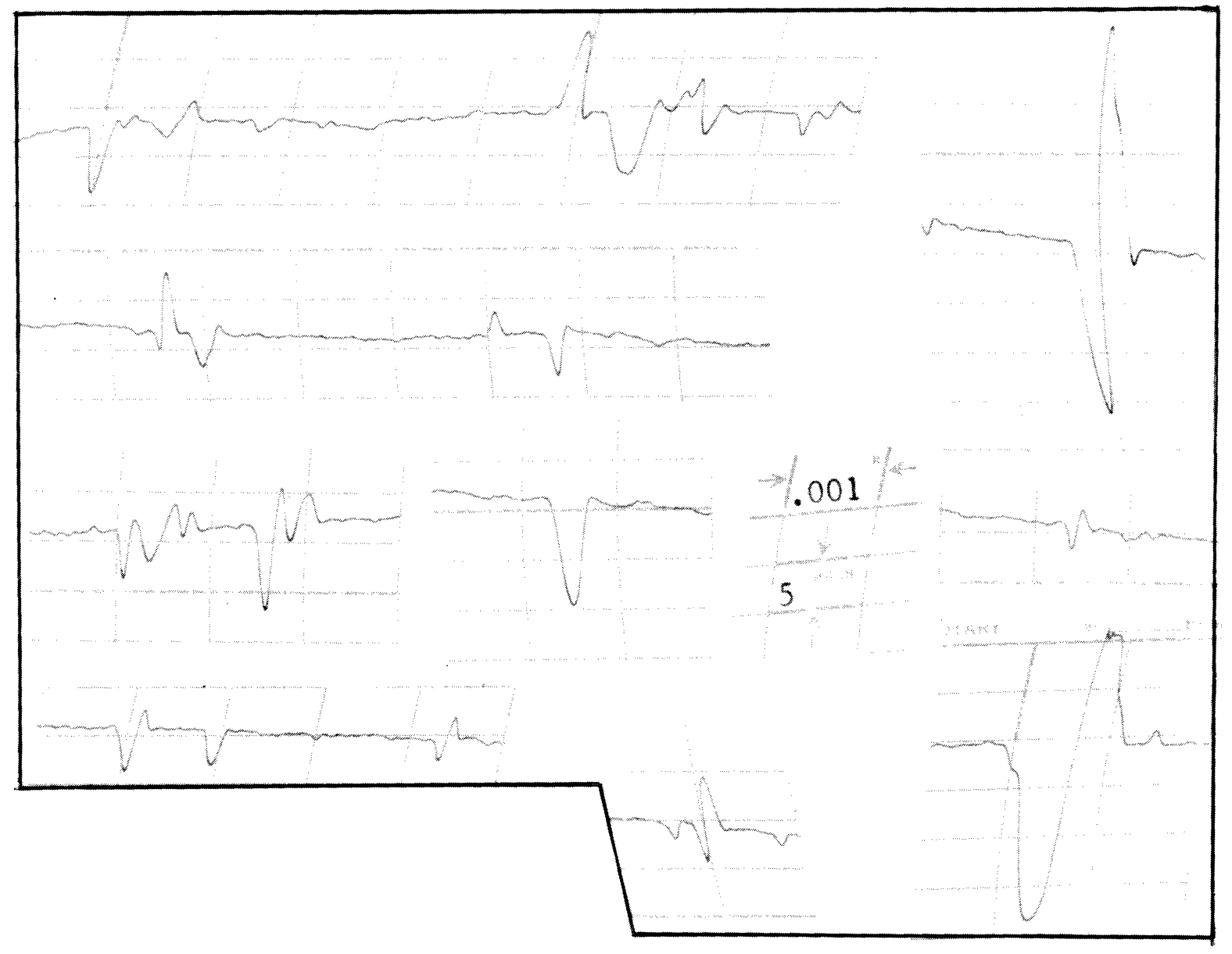

Fig. 7.--Typical photomicrographs and typical axial proficorder traces of cavitated surface of specimen No. 139-3 (304 SS) after 100 hours in water at a throat velocity of $200 \mathrm{ft} . / \mathrm{sec}$. for "standard cavitation" (a) nose area, (b) tail area. 
test specimen stock had been rolled. However, a specimen fabricated with rolling direction perpendicular to flow velocity pitted in the same way.

Both the tilting and the sensitivity of pit contour to throat velocity are evidence for the microjet as opposed to the classical Rayleigh shock-wave mechanism. Some slight tilting of a pit in the observed direction could result from the shock-wave model. The direction of the pit axis would be given by the addition of throat and sonic velocity vectors. The largest possible deviation from perpendicular would then result, since the axial velocity of the collapse center would be reduced by boundary layer effects, and the shock wave propagation velocity would be somewhat greater than sonic velocity for the undisturbed liquid. Maximum angle of tilt for maximum throat velocity is then on $1 \mathrm{y} \sim 2^{\circ}$, much less than that observed. For the microjet mechanism, the angle of impact of the jet is a result of complex factors involving tipping of the torus by velocity and pressure profiles, and interaction with the adjacent surface and fluid boundary layers. It cannot be predicted from information presently available.

The very large elongation of almost all the high-velocity pits is not easily justified on the basis of the shock-wave mode1, assuming that the pits are of the single-event type. However, it could we11 result from the impingement of a jet at an angle to the surface. Since it has been established by numerous detailed observations of the surface 9 that the pitting in this early stage of damage results from random single-event bombardment, the microjet mechanism seems to us the only 
plausible presently available explanation of these observations. The strong similarity of liquid impact craters enhances this conclusion.

\section{PIT SIZE, BUBBLE SIZE AND LOCATION DISTRIBUTIONS}

A. General. Throughout our investigations on cavitation damage, the polished face of the damage specimen (Figure 2) has been monitored for pitting, and in many cases pit counts made and classified as to size. Much of this data has been previously reported. $9,10,18,19$ More detailed size classifications at selected axial locations of pits from the mercury tests have now been made for two materials. These have been compared with number and size spectra of bubbles adjacent to the surface at these locations. ${ }^{12}$ Since the surface pressures at these locations were also measured, ${ }^{12}$ data relating bubble size and number density with the resultant pitting, under known flow conditions, has been obtained. Previously, a similar but less detailed study was made by Knapp ${ }^{20}$ using water and soft aluminum. For his experiment the ratio between number of bubbles apparently in a position to form a pit and pits actually formed was about 20,000. Similar large ratios have been reported for a vibratory cavitation device by $\mathrm{P}$ lesset ${ }^{21}$ and also observed in our own vibratory facility. 22

B. High-Speed Bubble Pictures. Data on the number of bubbles present along the surface of the test specimens per unit time were obtained $^{12}$ from high-speed movies taken through a plexiglas test specimen assembly (Figure 8) inserted through the wall of a stainless steel 


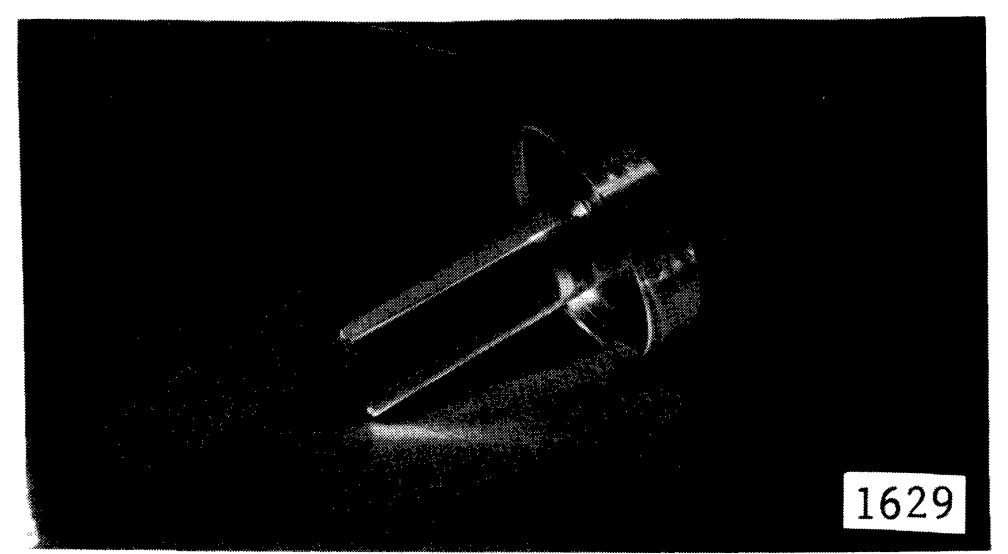

(a)

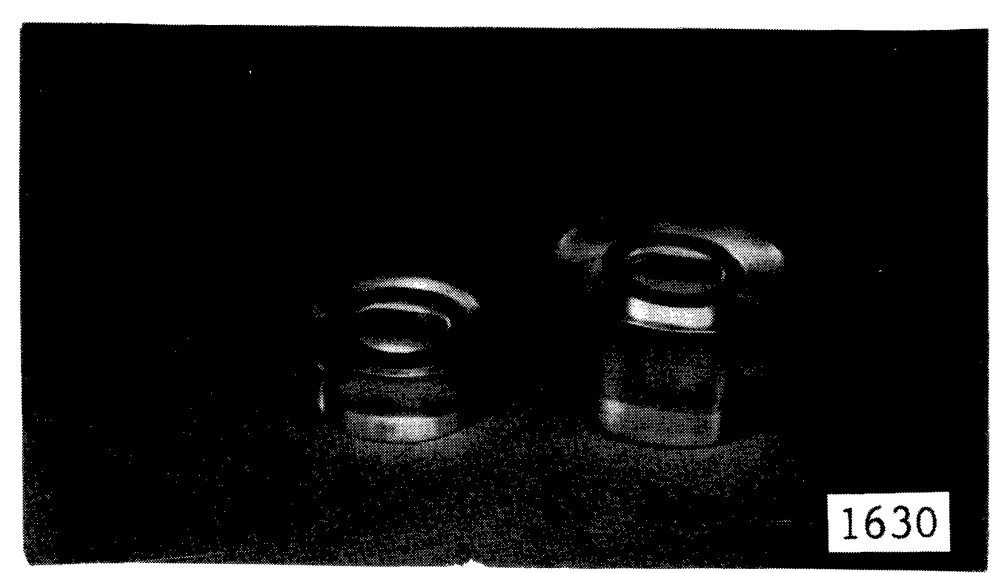

(b)

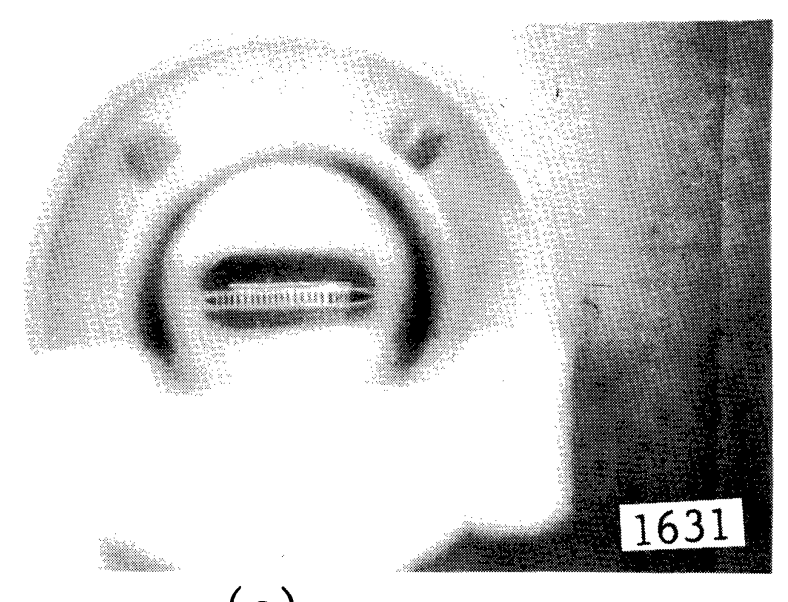

(c)

Fig. 8.--Photograph of transparent photographic specimen-holder combination. 
venturi (Figure 1). Only bubbles adjacent to the surface can be seen in the opaque mercury.

Figure 9 is a typical sequence. Close inspection shows several apparently spherical bubbles collapsing on the downstream portion of the specimen surface and along its sides. However, the photographic resolution for this arrangement did not allow meaningful conclusions on the mode of collapse. The pictures also indicate that for this cavitation condition ("standard cavitation"), for which the visual termination of the cavitating region is at the axial midpoint of the specimen, the upstream end of the specimen is covered with a more or less steady-state cavity.

C. Liquid Contact-Time Measurements. The existence of a steady cavity prompted the use of an "electrode specimen"12 (Figure 10). The high electrical conductivity of mercury was used to determine the liquid contact-time for various portions of the surface. Figure 11 shows typical results for various cavitation conditions and two throat velocities. Liquid mercury for "standard cavitation" was in contact with the surface at the axial midpoint for $\sim 50 \%$ of the time even though the motion pictures show this to be a region of intense cavitation activity. The percentage rises to nearly $100 \%$ for the downstream half, confirming that here the flow regime is a liquid continuum with isolated vapor bubbles. No fixed frequency for the size variations of the "steady" cavity was found.

D. Static Pressure Measurements. Static pressure measurements were made using a device similar to the electrode assembly (Figure 10) 


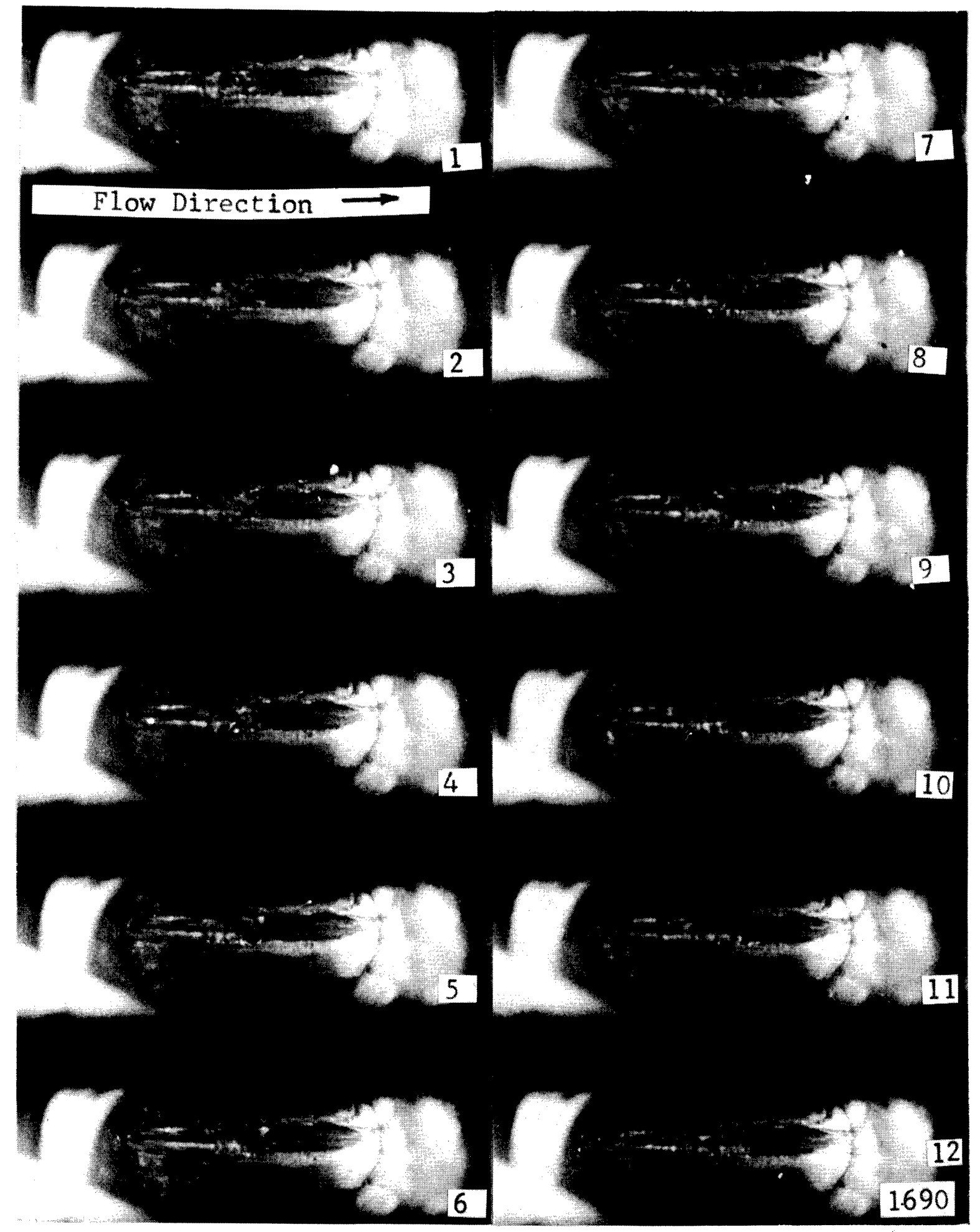

Fig. 9.--Typical sequence of pictures of cavitating flow on specimen surface for standard cavitation in mercury. 


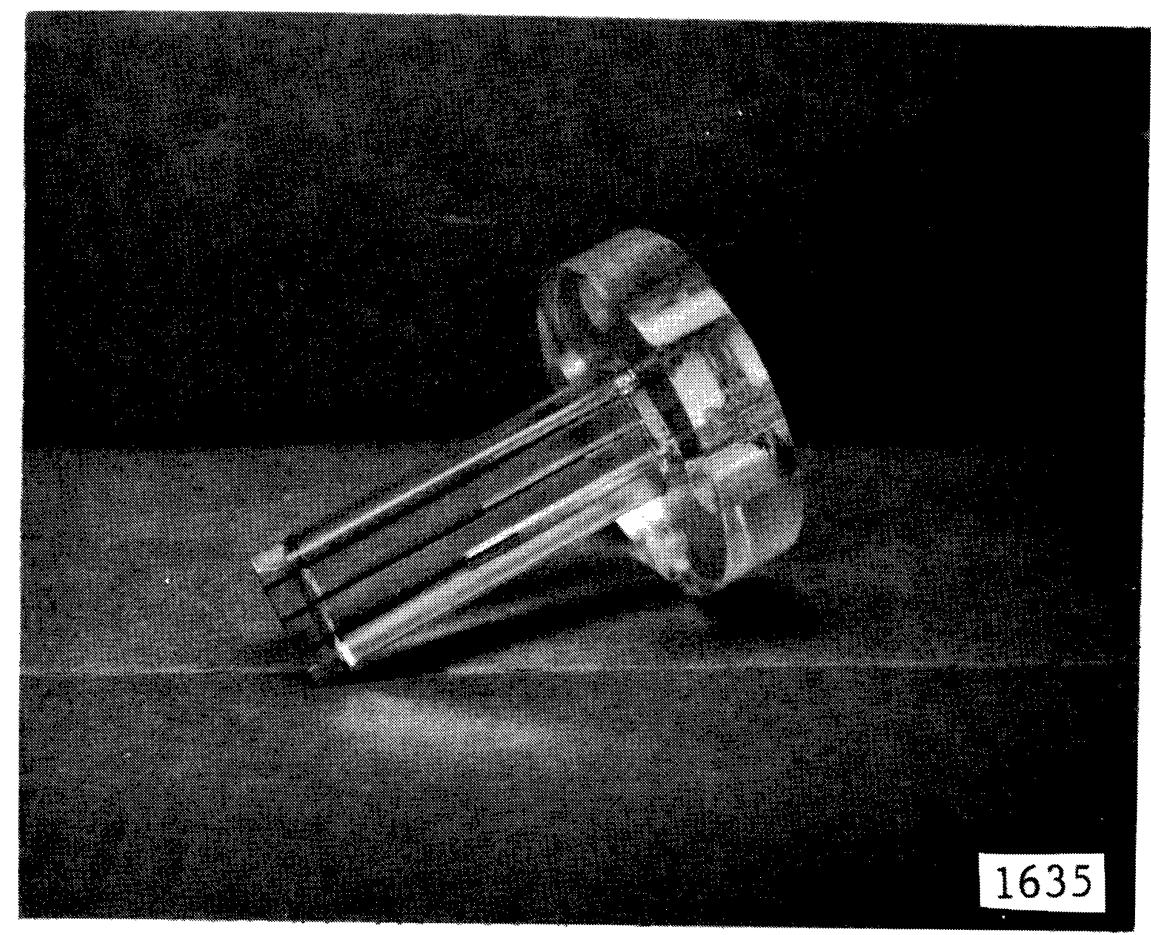

(a)

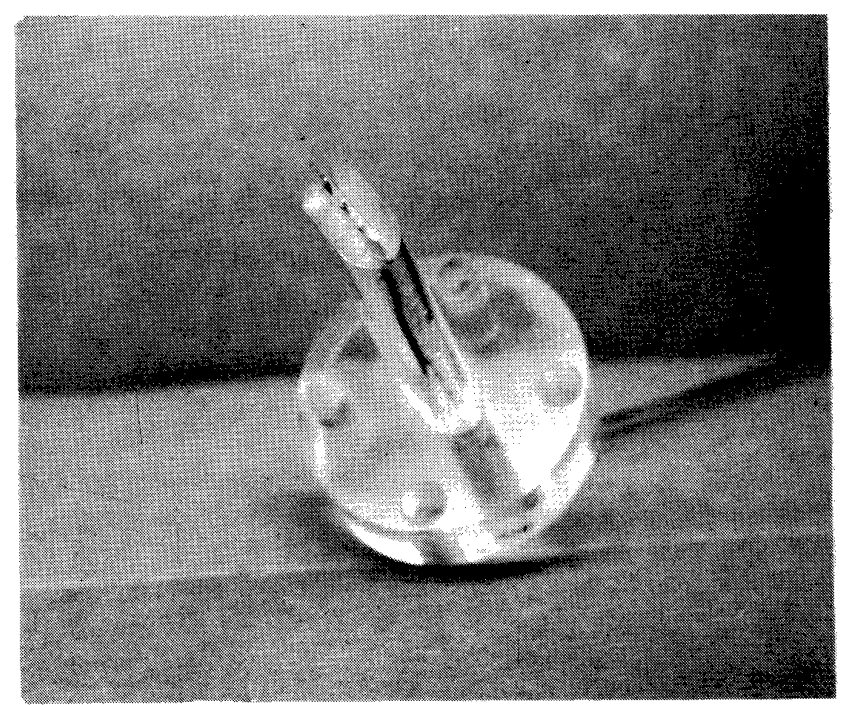

(b)

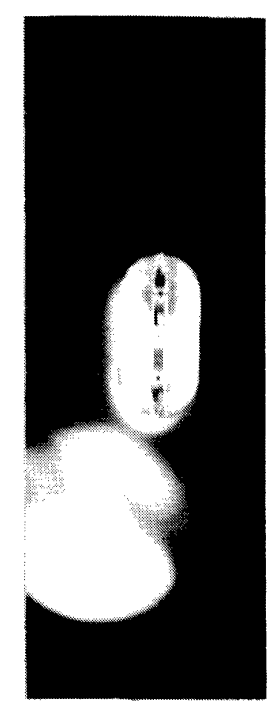

(c)

Fig. 10.--Photograph of electrode specimen-holder combination. 


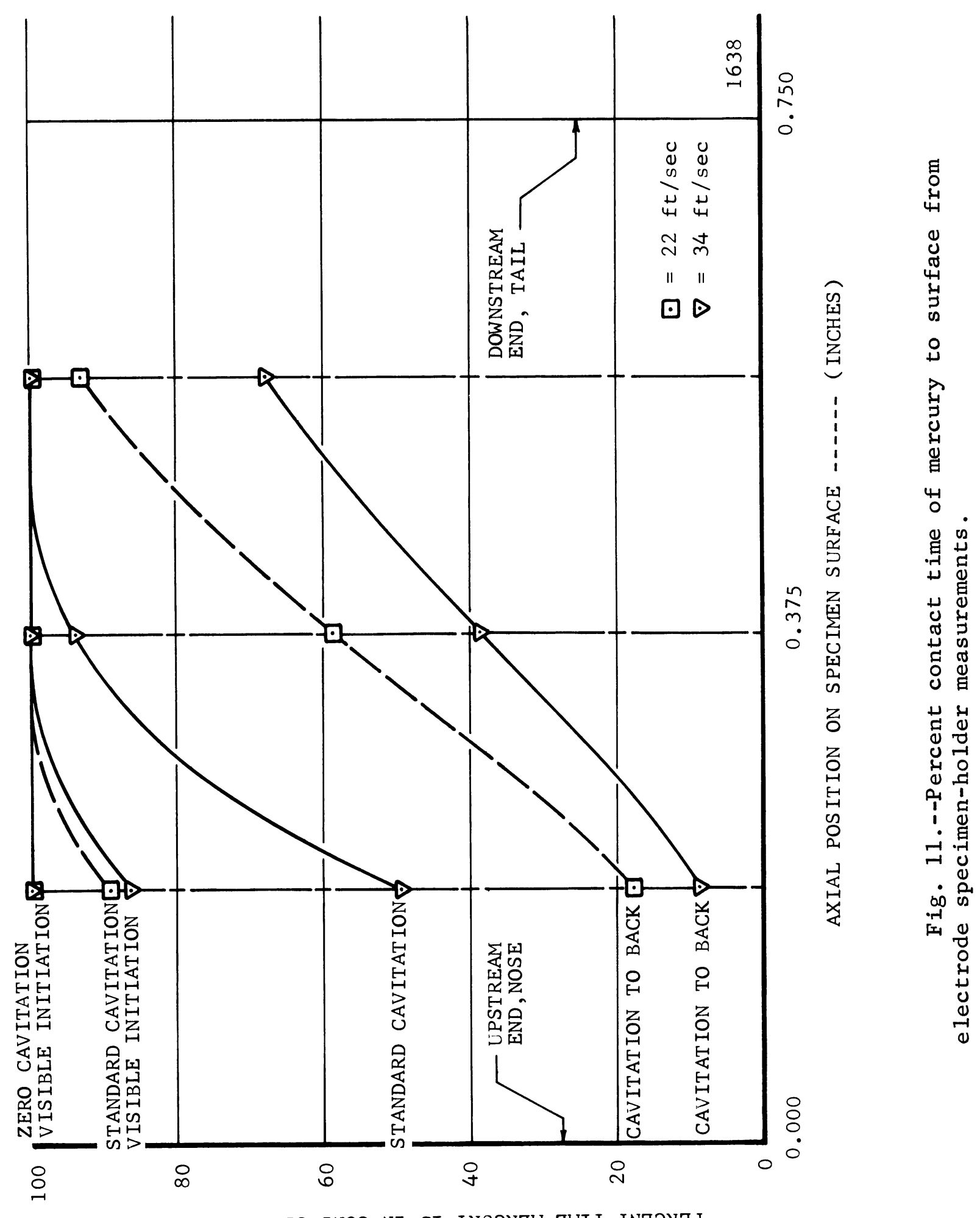

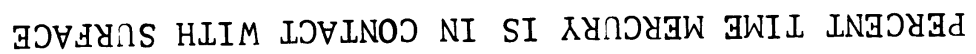


except that pressure taps replaced the electrodes. The mean pressure along the polished surface for the two specimen arrangement (for which the motion pictures apply) is well above vapor pressure for the entire length of the specimen (Figure 12). It is climbing very rapidly in the downstream portion where the single bubbles were observed. These pressure profiles are typical ${ }^{12}$ for the mercury and water tests.

\section{E. Pit Size and Location Distribution. Pit sizes were tabu-} lated $^{23}$ for three materials ${ }^{*}$ in mercury and one in water ${ }^{*}$ (Figure 13) for a band 6 mils in axial length across the polished face of the specimen in the region of most intense damage. The maximum in the pit diameter distribution occurs for a diameter of $\sim 0.05$ mils for stainless steel in mercury, and $\sim 0.025 \mathrm{mils}$ for the same material in water. The smaller pits for water presumably result from the weaker blows with the lower density fluid. For both fluids (not shown because of relative scale of figure), pits with a diameter up to several mils are sometimes found. No conclusions regarding the effect of mechanical properties on pit size are possible, since the materials examined, limited to those compatible with mercury, are of somewhat similar strength.

Figure 14 shows the pit size distribution for $\mathrm{Cb}-1 \mathrm{Zr}$ in mercury for different distances from the specimen leading edge. The number of larger pits increases with distance from the leading edge, while the number of smaller pits, and also the total number of pits, decreases.

*Table 1 lists applicable mechanical properties of materials used. 


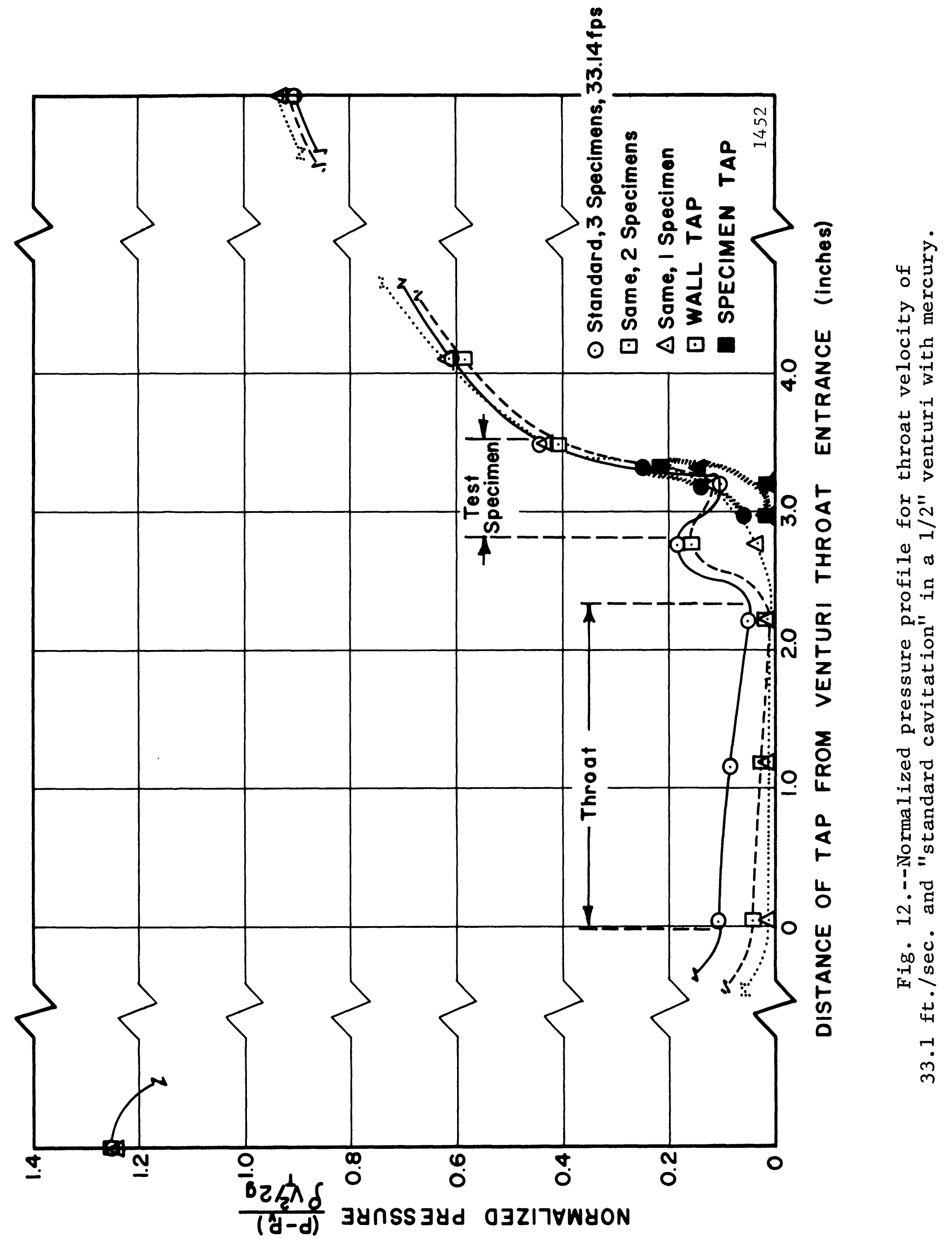




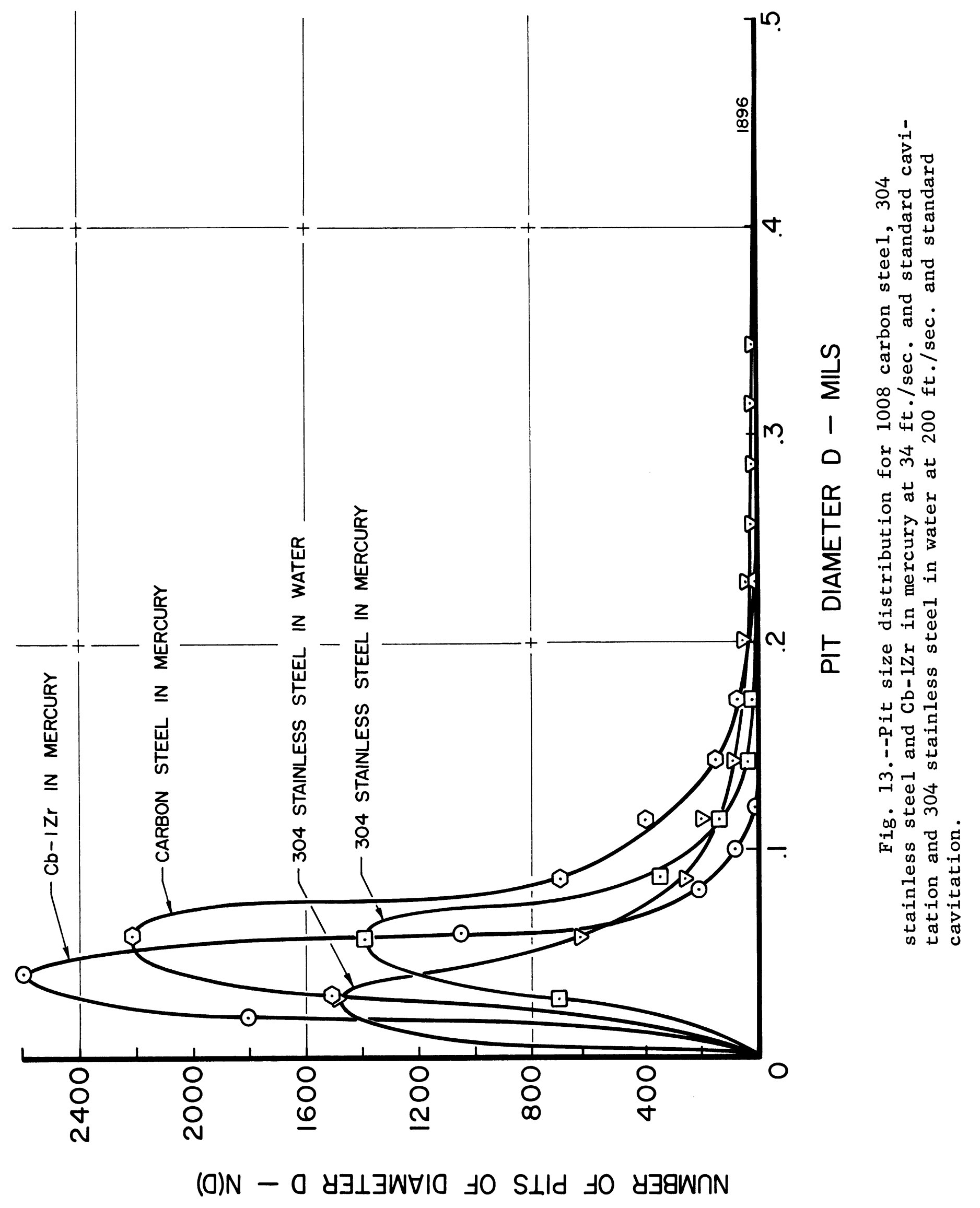




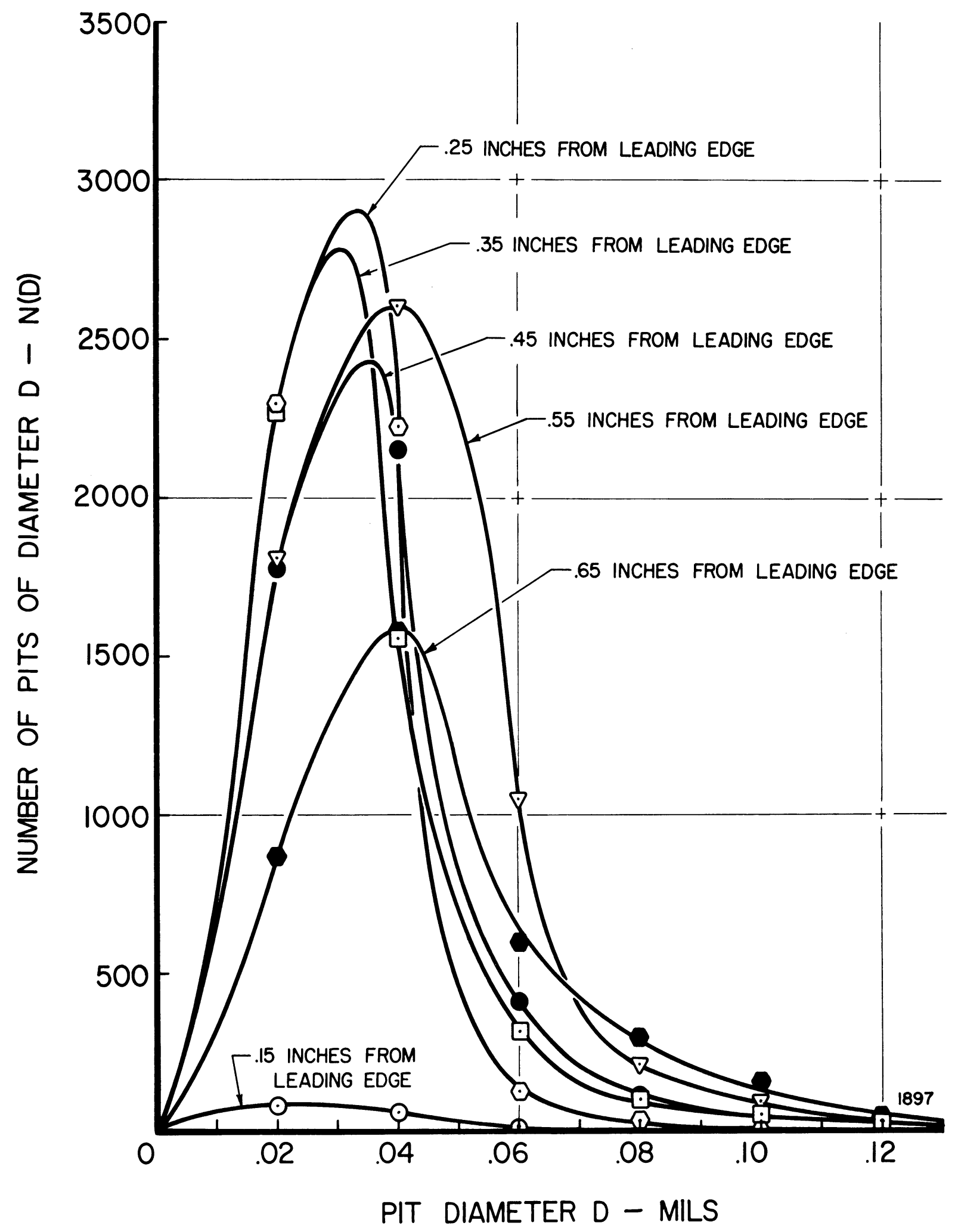

Fig. 14.--Pit size distribution vs. axial distance from specimen leading for $\mathrm{Cb}-1 \mathrm{Zr}$ in mercury at $34 \mathrm{ft} . / \mathrm{sec}$. and standard cavitation. 
This is as expected, since only relatively large bubbles penetrate into the high pressure region at the downstream end of the specimen. These then collapse under maximum pressure differential. For this reason, as we11 as their large size, they exhibit maximum damage potential.

F. Bubble Population vs. Pitting Rate. Detailed pit counts for a $\mathrm{Cb}-1 \mathrm{Zr}$ and a stainless steel specimen, exposed to "standard cavitation" in mercury at $34 \mathrm{ft} . / \mathrm{sec}$. throat velocity, allowed a comparison between bubble and pit number and location distributions for each material (Figure 15). Total numbers of pits/sec. as a function of distance from specimen leading edge for both $\mathrm{Cb}-1 \mathrm{Zr}$ and stainless steel along with the static pressure above vapor pressure (suppression pressure), and the number of bubbles observed per second in the high-speed motion pictures, are shown.* The curves are extrapolated for the full specimen length, i.e.g somewhat beyond the actual data points. The bubble population decreases strongly for increasing distance from the leading edge as the suppression pressure increases from relatively small to quite substantial values. This general trend is as expected, although the curve shape cannot be forecast. The pitting rate increases strongly for both materials roughly in the region of most rapid pressure increase, presumably since a substantial suppression pressure is required to cause damaging bubble collapses. Eventually, however, as the suppression pressure is further increased, the pitting rate decreases since, although

\footnotetext{
*No bubble size spectrum could be obtained. However, the diameters ranged from $\sim 5$ to $\sim 30 \mathrm{mils}$.
} 


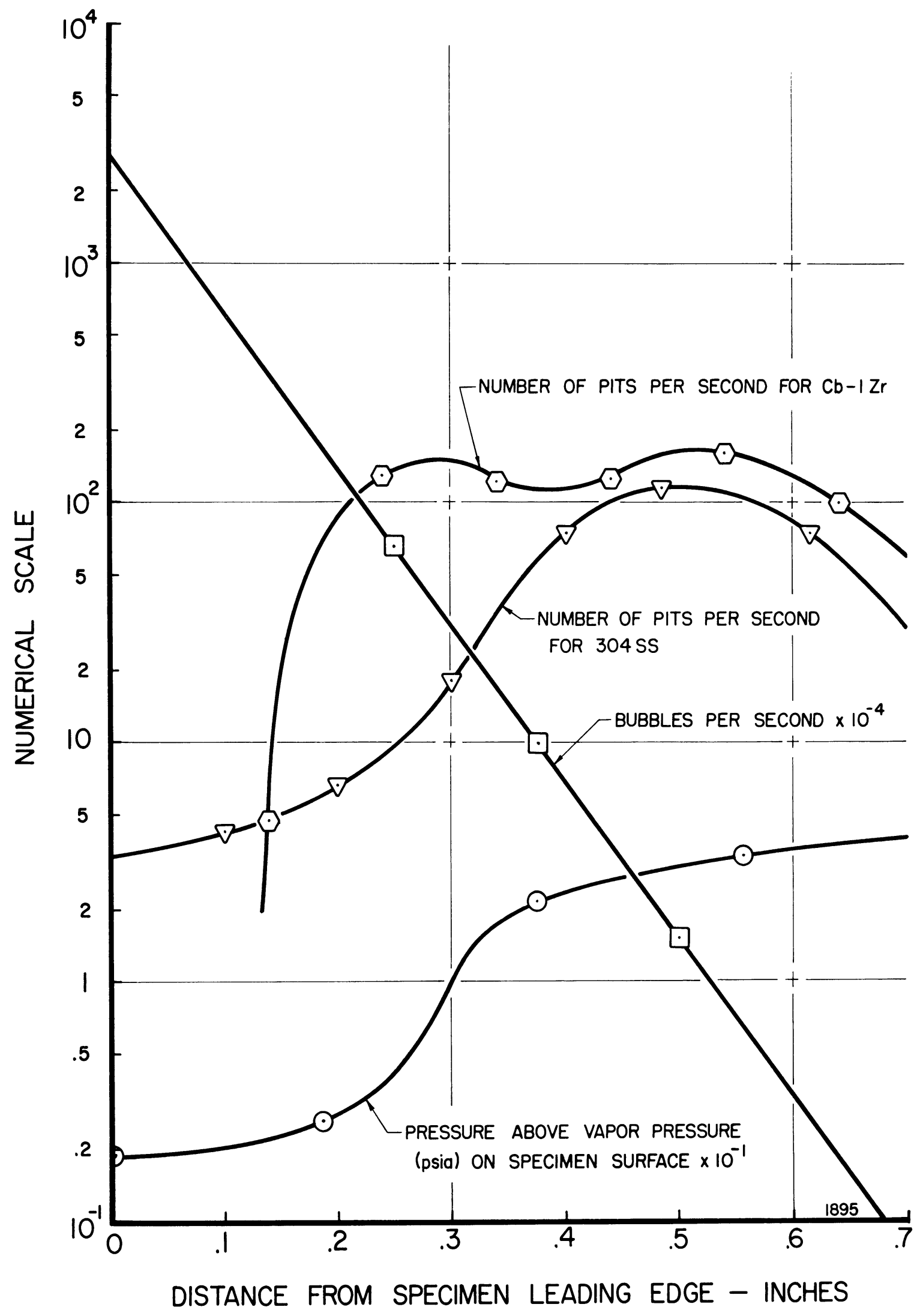

Fig. 15.--Distribution per unit time of pits, bubbles and pressure above vapor pressure on test specimen polished surface vs. distance from specimen leading edge for $\mathrm{SS}$ and $\mathrm{Cb}-1 \mathrm{Zr}$ in mercury at $34 \mathrm{ft} . / \mathrm{sec}$. and standard cavitation. 
the bubble collapse violence is increasing, the number of bubbles decreases at such a rate that the latter factor becomes controlling. Finally, the rapid rise in pitting rate for the weaker material $(\mathrm{Cb}-1 \mathrm{Zr})$ occurs at a lower suppression pressure than for the stainless steel, since its damaging threshold for single-event pitting in terms of imposed pressure-time regime is less (Table 1 ).

Figure 16 shows the ratio between number of bubbles and number of pits per unit time for the $\mathrm{Cb}-1 \mathrm{Zr}$ and stainless steel, both as a function of axial position and suppression pressure. This ratio decreases strongly as the suppression pressure is increased (as expected) ranging from about $10^{8}-10^{9}$ for low suppression pressure to about $10^{4}$ $10^{5}$ for maximum suppression pressure. The values at the higher pressure end are approximately in agreement with previously discussed ratios from vibratory facilities, wherein the collapsing pressure differentials are relatively large as compared to the venturi tests.

As expected, the ratios for the weaker material are less than for the stronger.

\section{G. Energy Considerations. It is instructive to compare the} orders of magnitude of collapse energy available at the start of bubble collapse to the energy of distortion evident in the observed pits, even though only approximate ideas can be formed from the present data. Assume, as a very rough approximation, an average bubble initial radius, $\overline{\mathrm{R}}_{\mathrm{b}}$, which is not a function of axial position. Then the available energy per bubble collapse is proportional to suppression pressure, 


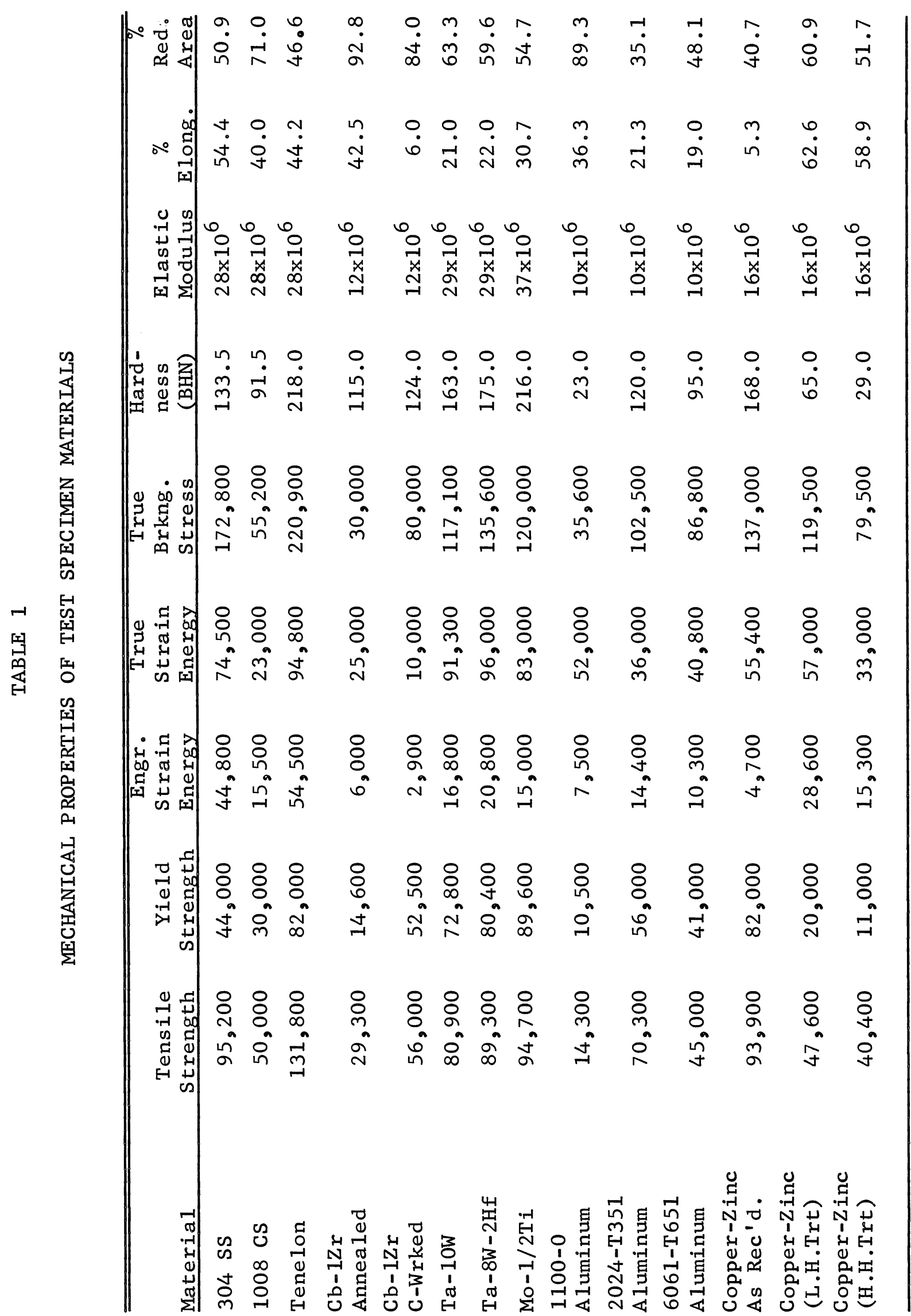




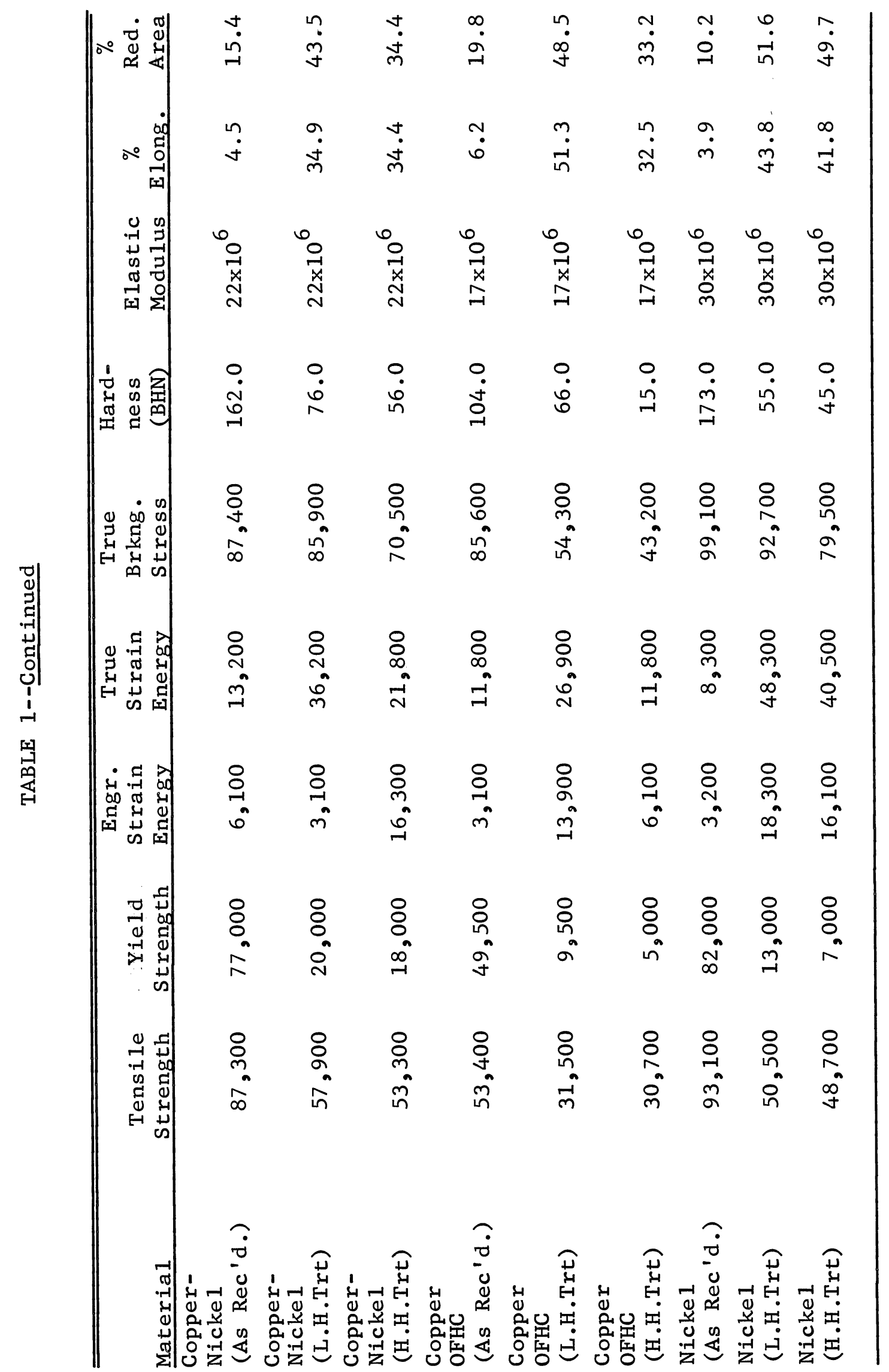




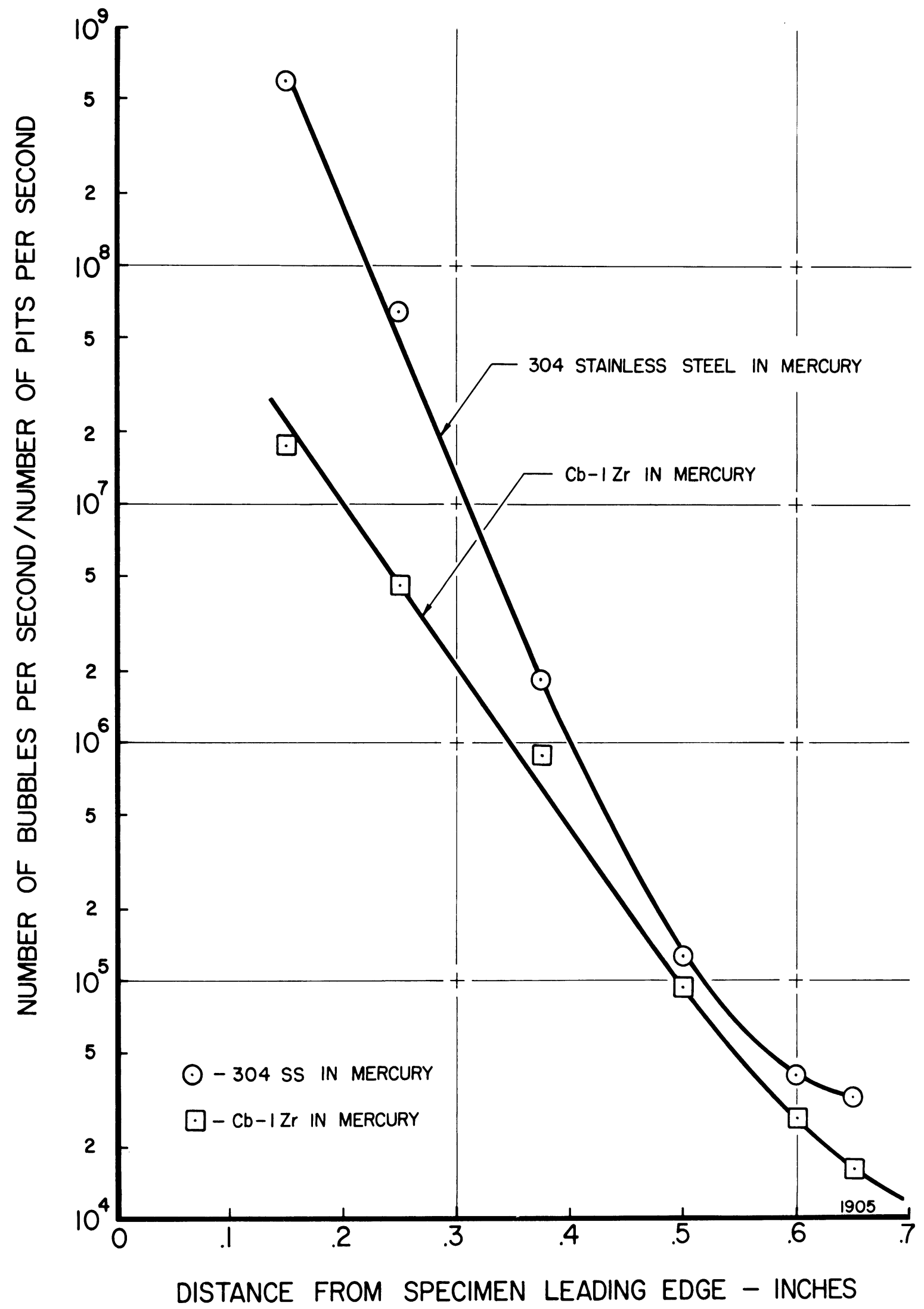

Fig. 16.--Ratio of observed bubbles per pit formed on surface per unit time vs. distance from specimen leading edge for 304 SS and $\mathrm{Cb}-1 \mathrm{Zr}$ in mercury at $34 \mathrm{ft} . / \mathrm{sec}$. and standard cavitation. 
i.e.,

$$
E_{b}=4 / 3 \pi \bar{R}_{b}^{3}\left(p-p_{v}\right)
$$

Assume also that $\bar{R} \cong 8$ mils (roughly a mean between the extremes observed).

The energy required to form a pit can be taken very approximately as the product of strain energy to failure (Table 1) and volume removed. Assume, as a rough approximation, that volume removed equals the product of the surface area of the depression and $1 / 20$ of the diameter, since a typical diameter-to-depth ratio is about 20. Then, assuming an average pit diameter, $\overline{\mathrm{D}}_{\mathrm{p}}$ \% equal to 1.5 times the peak diameter of the distribution curve for the particular material to account for the tail of the distribution curve (Figure 13):

$$
E_{p}=0.05 \times \pi\left(1.5 \bar{D}_{p}\right)^{3} \quad \text { (strain energy to failure) }
$$

and, as an approximation, use the "engineering strain energy" from Table 1.

The ratio of total bubble collapse energy available to total distortion energy actually observed is then:

$$
\frac{\text { Bubble Collapse Energy }}{\text { Distortion Energy }}=\frac{\sum E_{b}}{\sum E_{p}}=\frac{N_{b} E_{b}}{N_{p} E_{p}}
$$

Figure 17 shows this ratio as a function of suppression pressure for the two materials. It decreases by orders of magnitude for either material as the suppression pressure is increased, but is never $\gtrless_{10}^{9}$. The range 


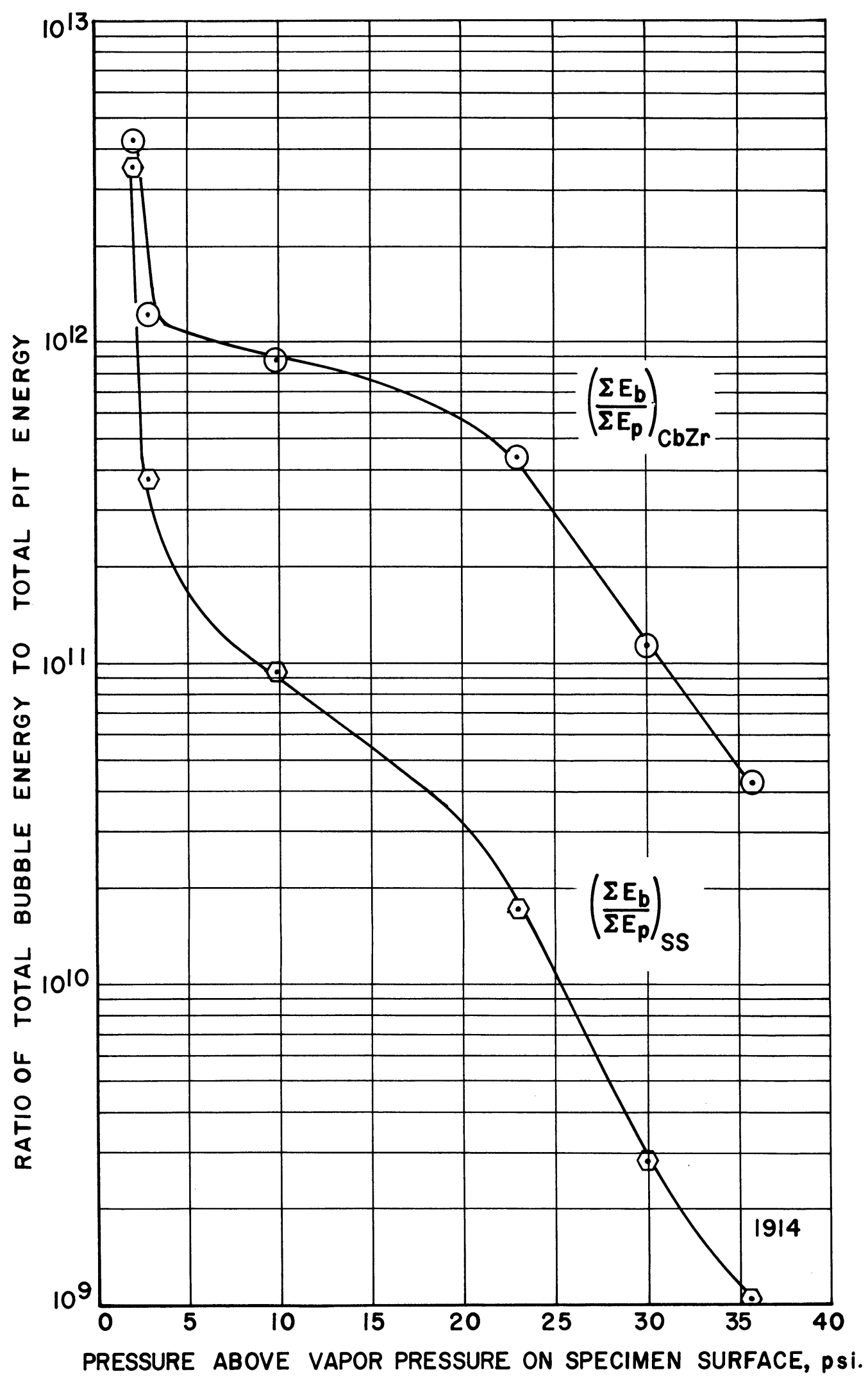

Fig. 17.--Ratio of calculated total available bubble collapse energy to total surface distortion energy vs. pressure above vapor pressure on specimen surface. 
in this ratio is greater for the stainless steel than for $\mathrm{Cb}-1 \mathrm{Zr}$, indicating that comparatively less damage results to the stainless steel from the low pressure collapses than to the $\mathrm{Cb}-1 \mathrm{Zr}$. This was also evident in Figure 15. As indicated in Figure 17 the cavitation process is less "efficient" in damaging the $\mathrm{Cb}-1 \mathrm{Zr}$ than the stainless steel at the high-pressure end of the specimen. It may eventually be possible to justify such trends in terms of coupling parameters between the fluid and material.

Figure 18 shows the ratio of available bubble collapse energy to pit distortion energy for a single bubble-pit combination as a function of suppression pressure for the two materials. These curves are derived from Figure 17, dividing the ratios plotted therein by the ratio of bubbles to pits as taken from Figure 16. Even on this basis the ratio is $\boldsymbol{>}^{3} 0^{3}$, so that apparently only a very small portion of the available energy in a damaging bubble collapse actually appears as permanent distortion of the material. The ratio is again a function of suppression pressure and the material, so that its full explanation must include coupling parameters between fluid and material.

H. Implications for Damaging Mechanisms. The first observation of very large ratios between numbers of bubbles and pits formed is apparently that of Knapp. 20 The present observations are far more detailed and show that the ratio can be orders of magnitude larger in low suppression pressure regions and with stronger materials than that which Knapp observed for soft aluminum. 


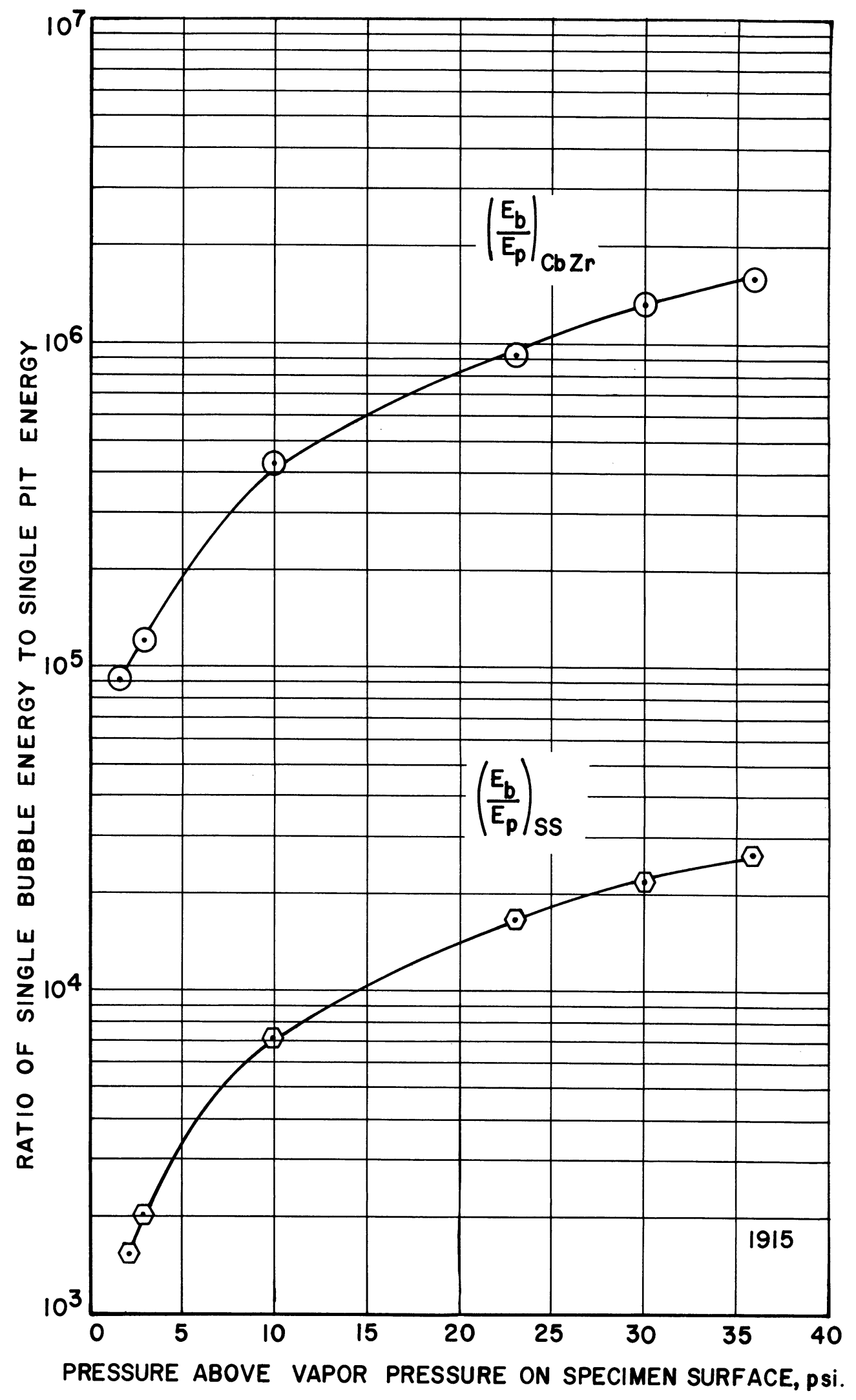

Fig. 18.--Ratio of calculated energy per single bubble collapse to surface distortion energy for a single pit vs. pressure above vapor pressure on specimen surface. 
These enormous ratios indicate the existence of a very sensitive sorting mechanism between those bubbles which cause damage and those which do not. Such a sorting mechanism is provided more naturally by the jet impact damage mechanism than by the Rayleigh shock wave mechanism, since, although both models require a precise proximity to the surface, another order of magnitude of selectivity is required for the impact model with its directional dependence. This is absent in the symmetrical Rayleigh model. Although we believe the origination of these thoughts are independent, we note a similar line of reasoning in a recent report by E11is. 24

IV. DAMAGE RATES AS FUNCTION OF FLUID AND MATERIAL PROPERTIES

A. Genera1. Previous papers ${ }^{9,10,25}$ and reports $12,18,19,23$ presented considerable data on damage rates as a function of fluid and material properties from our venturi tests. Generally the rates are highly non-linear, including several maxima in some cases. ${ }^{19}$ Also no simple correlation, generally applicable to all the materials tested in both water and mercury, in terms of the conventional mechanical properties appears to exist. Further, damage rates are affected by prestress existing in the test material ${ }^{25}$ and by trace quantities of any relatively volatile fluid component (gaseous or liquid) in the test liquid. 25 Additional previously unpublished information on damage rates as affected by fluid and material properties is now presented.

B. Mercury vs. Water. No conclusions can be drawn relating the comparative damaging capabilities of water and mercury under "similar" 
flow conditions; i.e., identical geometry, velocity, and extent of cavitating region. Due to facility capabilities limitations no effective overlap of velocity between the two fluids was achieved. The bulk of the mercury data was obtained at a throat velocity of $\sim 34 \mathrm{ft} . / \mathrm{sec}$. and the water data at $\sim 200 \mathrm{ft} . / \mathrm{sec}$. Also, a two-specimen venturi (Figure 1) was used for mercury, and a three-specimen arrangement (Figure 1) for water. Although not initially realized, this geometrical variation is significant. In addition, earlier mercury tests, wherein the damage was considerably greater than that later obtained, were found to have been conducted using mercury with trace quantities of water and in a pitted venturi. Later data with "dry" mercury and repaired venturi showed significantly less damage and was used for the damage correlations. The damage rate with $34 \mathrm{ft} . / \mathrm{sec}$. throat velocity in "dry" mercury was found to be only slightly greater than that with water at $200 \mathrm{ft.} / \mathrm{sec}$. Since it was found that the velocity effect in these venturis was much less than previously reported for other flow conditions, $20,28, \mathrm{e} . \mathrm{g} \cdot$ and since no reliable velocity-damage relation for the venturi is known, no good comparison of mercury-water damage capabilities can be made.

\section{Effects of Grain Shape and Size. Examination of surfaces}

that had been etched and photographed before and after cavitation showed that the location of crater-type pits is completely random with respect to grain boundaries $12,18,23$ although fatigue-type pits have been noted to follow grain boundaries in some cases. 18

Mousson $^{26}$ and Boetcher ${ }^{27}$ indicated a substantial decrease of damage with decreasing grain size with mechanical properties held 
approximately constant. A more recent test ${ }^{28}$ with $\mathrm{Cb}-1 \mathrm{Zr}$, wherein the mechanical properties were not held constant, showed the opposite effect

In the present study, tests in water on four alloys of copper, zinc, and nickel were available for a variety of heat-treat conditions. From this data, tests for which the mechanical properties are roughly the same and only the grain size varies can be selected. Figure 19, in agreement with Mousson $^{26}$ and Boetcher, ${ }^{27}$ shows a substantial decrease in damage as grain size is reduced from ASTM Grain Size 非1 to about 非6. Further reduction to Size 非 8 is accompanied by an increase in damage. However, this portion of the curve is not comparable with the rest since the grains were substantially elongated due to cold-work. It is clear from these results and those of Mousson and Boetcher that damage cannot be correlated solely in terms of mechanical properties.

D. Cavitation Surface Hardening. The pit size distributions show that force-time regimes of varying magnitude are applied to a cavitated surface in a given flow situation. Thus a surface is exposed to many blows of an intensity below the damaging threshold, but still capable of causing cold-work, during a sustained cavitation test. In fact, substantial surface hardening of cavitated specimens was previously observed by Boetcher. 27

In the present study, ${ }^{23}$ microhardness profiles were measured along the axial centerline of the polished surface on fully-annealed copper, copper-zinc, and copper-nickel alloys at selected time intervals during a 100 hour water cavitation test. Figure 20 shows these profiles 


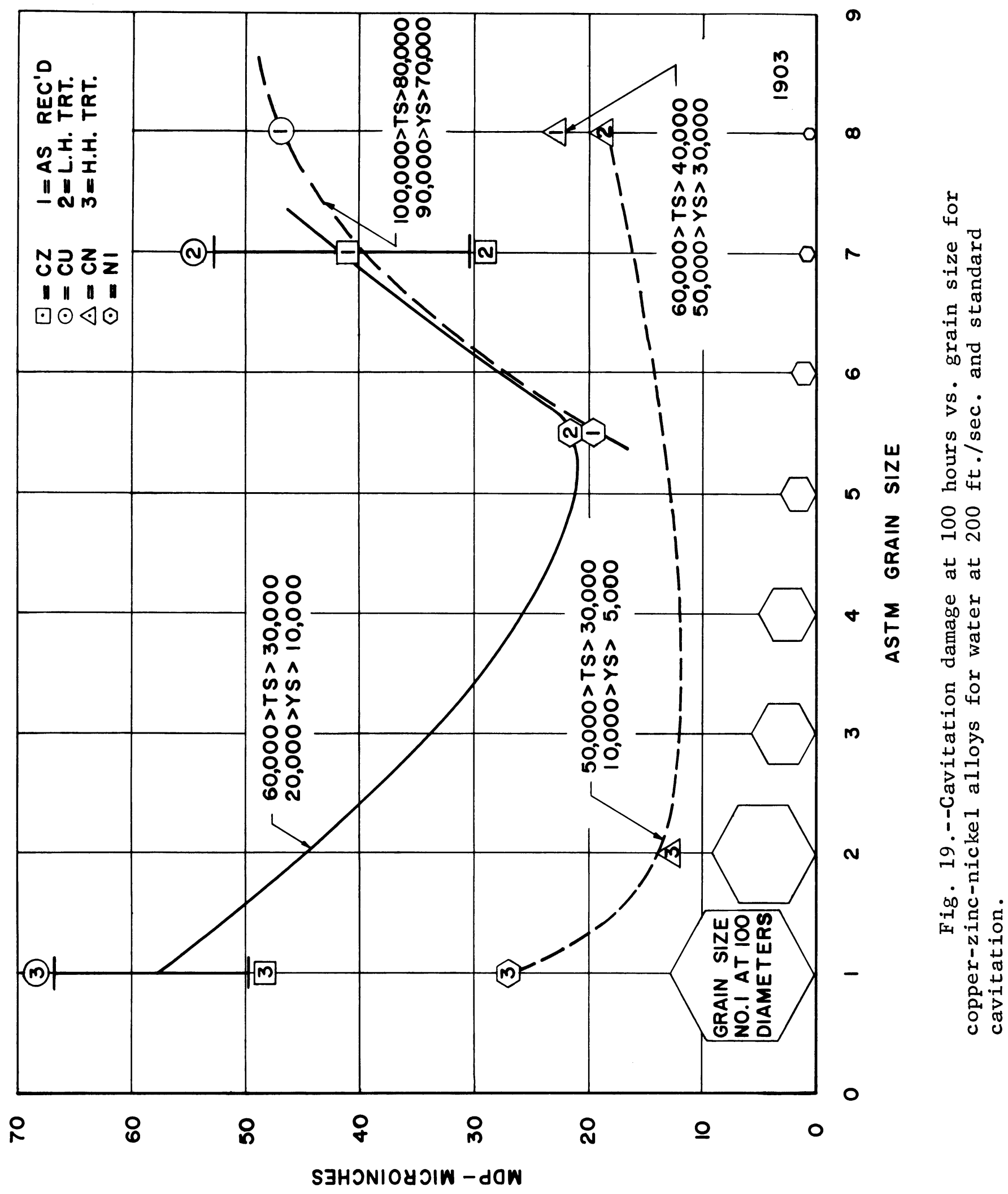




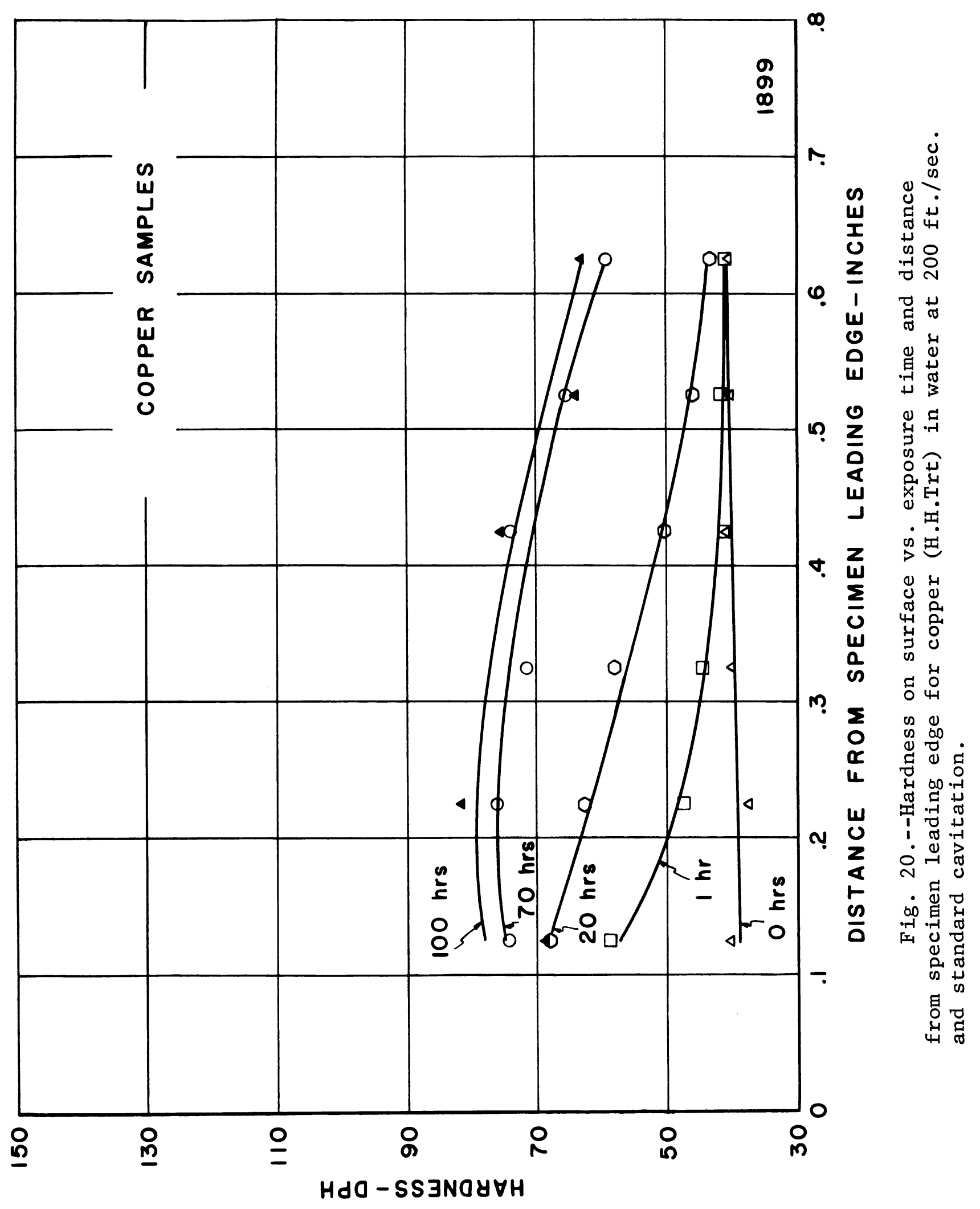


for the copper samples where the increase of hardness during the test was greatest and most uniform. It is most pronounced for the upstream portion of the surface. That the increase should be greatest at the upstream end and for the softest material (copper) indicates that the bubble implosions in this low pressure region are very numerous and relatively weak (as already indicated from consideration of the pressure profiles and bubble-to-pit ratio distribution). Thus they are effective only on the weakest material. With such a material in this flow regime the blows effective in producing cold-work cover most of the surface, and thus would be expected to cause a substantial increase in hardness.

Figure 21 shows the microhardness profile for copper-zinc alloy. Although this alloy was considerably harder initially than the copper (Table 1), some increase in hardness is still noted for the upstream portion. The smaller increase for the harder material is reasonable, since the surface is exposed to a smaller number of blows sufficiently intense to cause cold-work. The hardening effect is negligible for the downstream end of this harder material. Only a small portion of the surface in this region is exposed to sufficiently intense blows, since the number of bubbles is much reduced.

It is clear that surface hardening of the type observed can to some extent inhibit further damage.

\section{E. Correlations of Damage Rate with Mechanical Properties.}

Throughout our cavitation damage studies attempts have been made to correlate cavitation damage in terms of various mechanical properties and/ or coupling parameters between material and fluid, ${ }^{12,23}$ using a least 


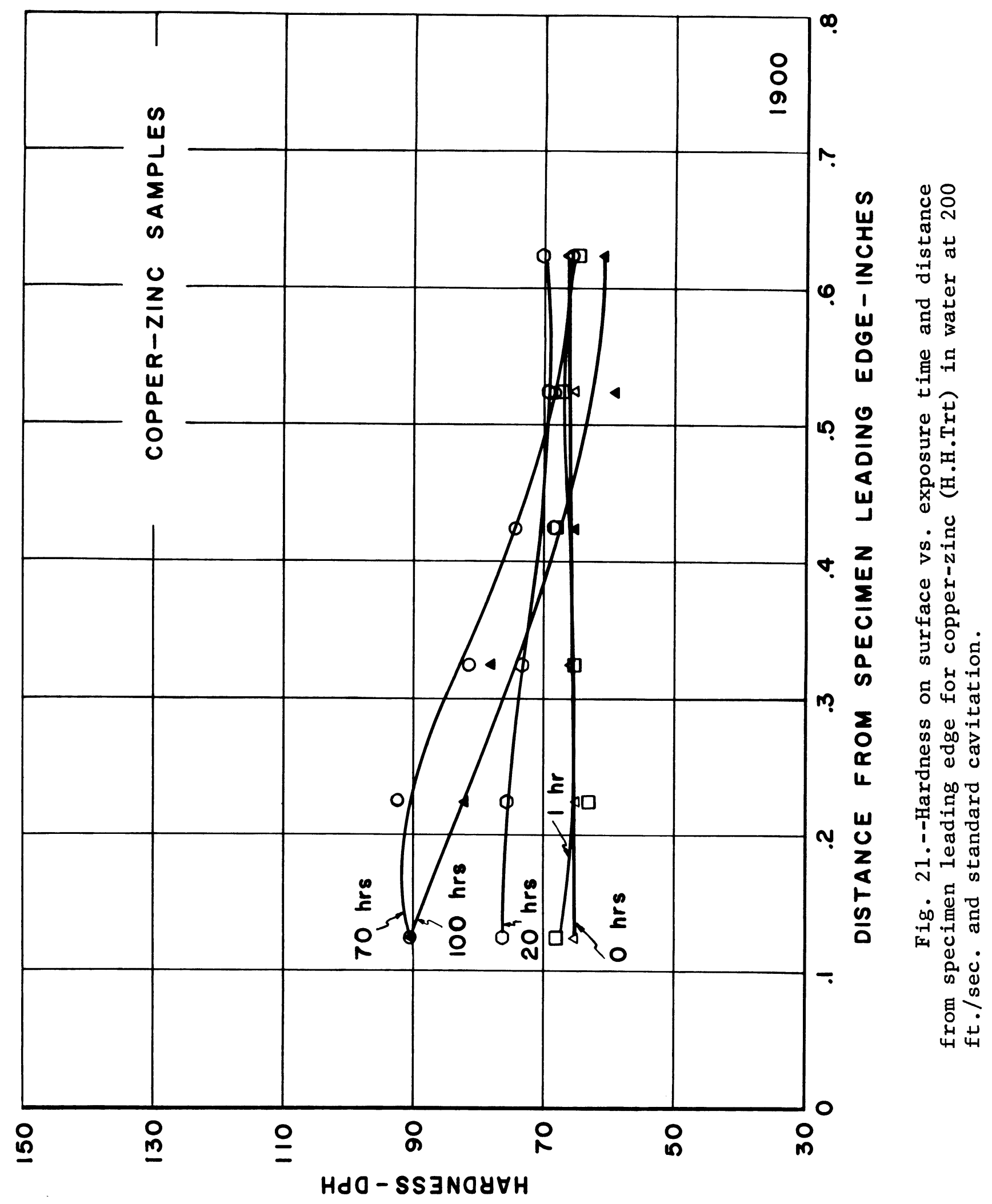


mean square fit regression analysis. ${ }^{12}$ It has not been possible so far to obtain a simple general correlation reasonably applicable to the two fluids and various materials. Similar attempts have been made for our vibratory tests with limited, although somewhat greater, success, $29, \mathrm{e} \cdot \mathrm{g}$. possibly because of the lesser role played by corrosion in these more accelerated tests. The lack of positive results in spite of the comprehensive damage data and accurate mechanical property data (measured for the specific stock tested) suggests that a damage correlation in terms of the conventional mechanical properties, obtained under semi-static loading conditions, cannot be expected, since cavitation surface loading is highly transient.

Tables 2 and 3 show the correlations obtained with various applicable mechanical properties considered singly for both mercury and water. High "F leve1" and "Coefficient of Determination" (Coef. D.), and low "Std. Error" can be considered as figures of merit for these correlations, which are arranged in order of descending "Coef. D." The mechanical properties used are defined in the appendix.

Note that the properties providing the most successful correlations in water and mercury differ substantially, and that there is also some difference for the different water durations.

Table 4 shows the best multiple property correlations obtained for both mercury and water. This is included to show the complexity of the resulting relations, and the fact that they differ greatly for the two fluids. 


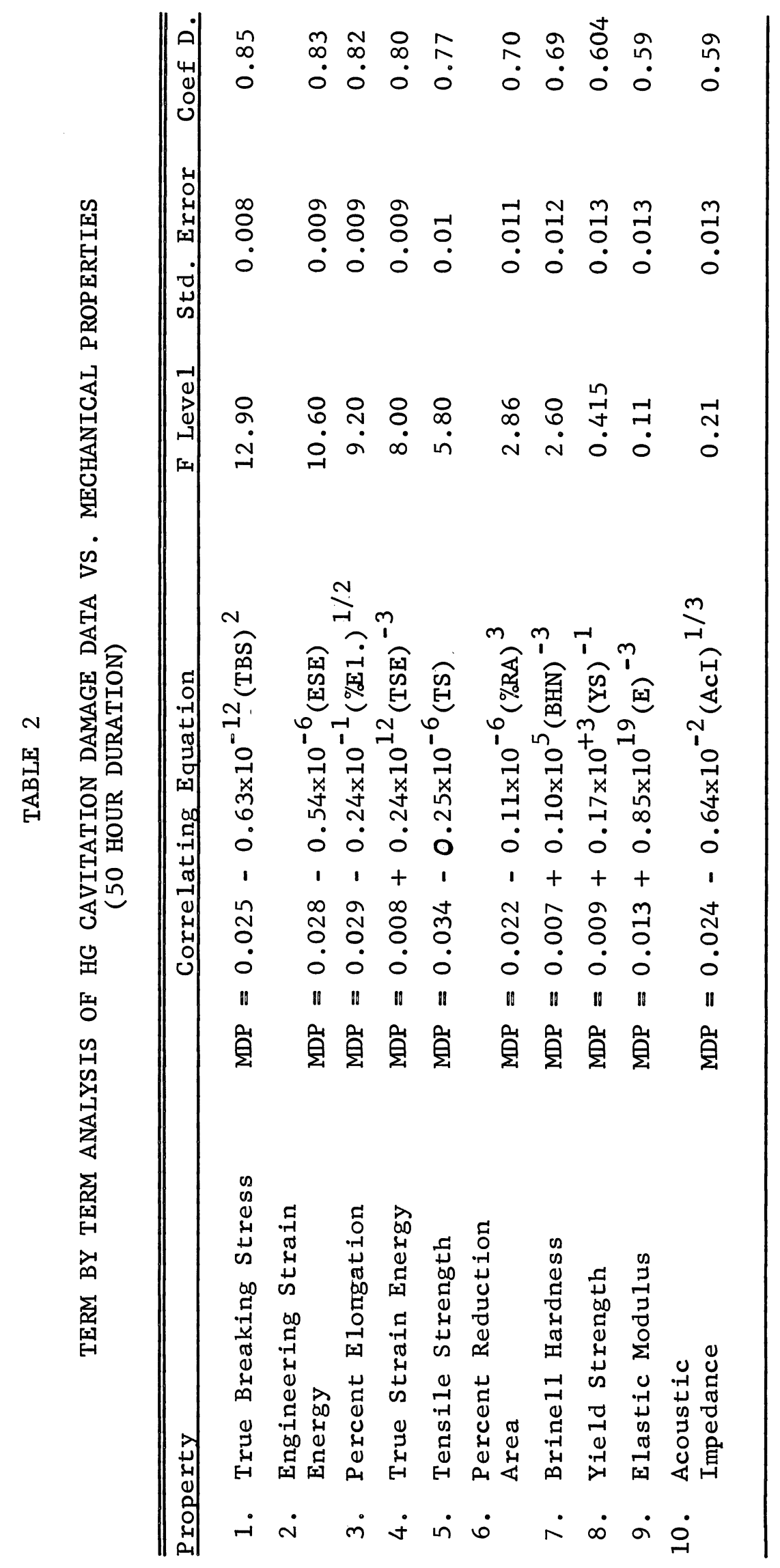




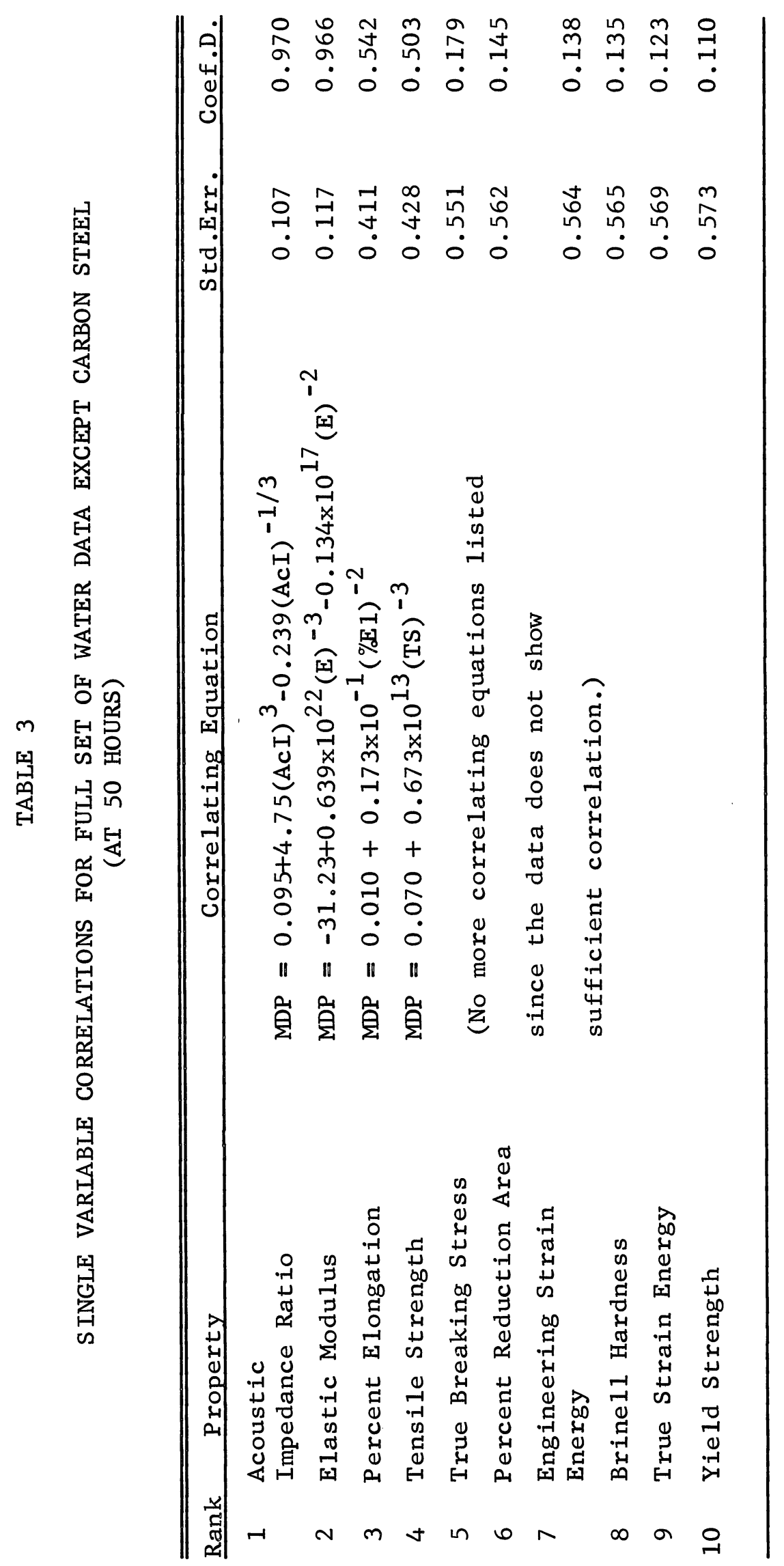




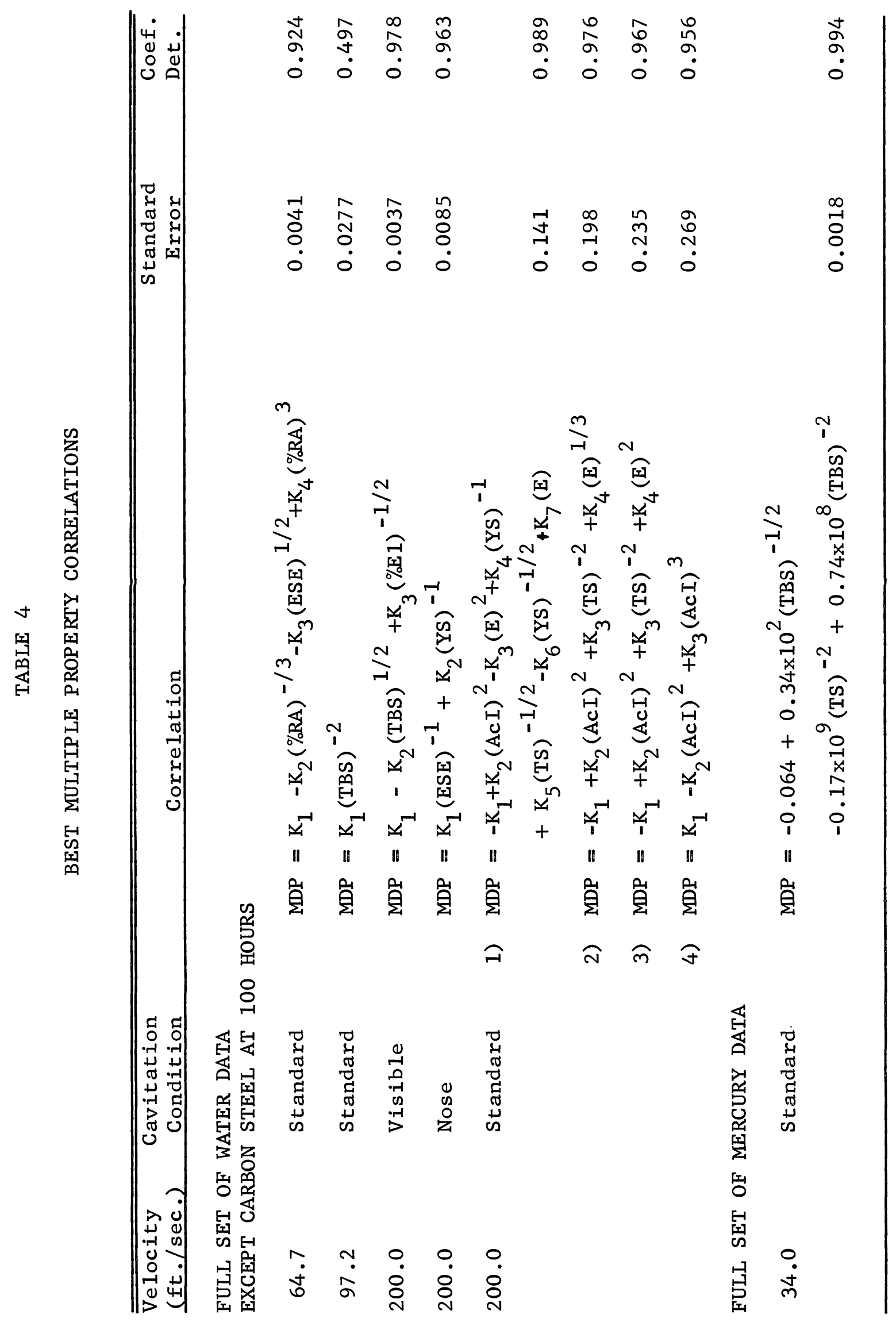




\section{CONCLUSIONS}

Detailed observations on cavitation pitting and the accompanying flow regime in cavitating venturis, using both water and mercury as test fluids, have been made. These various pieces of evidence, which are fully described in the paper, indicate the likely major importance of an impacting microjet damage mechanism as opposed to the classical Rayleigh shock-wave mechanism. This tentative conclusion seems especially pertinent to flows involving strong pressure gradients. Such is the usual case for many types of fluid flow machinery.

It is further concluded that there is a substantial effect of grain size on cavitation damage, assuming mechanical properties are not varied, so that materials with smaller grains are more cavitation resistant.

It has also been demonstrated that surface work-hardening of some alloys by cavitation attack is significant.

Finally, it is tentatively concluded that a general correlation between the conventional semi-static mechanical properties and cavitation damage rates cannot be expected. 


\section{APPENDIX \\ DEFINITION OF CAVITATION CONDITIONS}

The degree of cavitation as defined in the overall damage investigations in this laboratory and in this particular investigation differ between mercury and water. In the mercury venturi, where only two specimens are used, cavitation initiates at the throat outlet for all velocities used thus far, and the degree of cavitation applied to the mercury tests describes the extent of the cavitation cloud starting at the throat outlet and extending downstream to the point indicated, i.e., "cavitation to nose" is self explanatory. However, in the case of water, where three specimens are used, thus presenting more blockage to the venturi, the cavitation cloud initiates on the nose of the specimens and extends downstream to some point arbitrarily labeled by the degree of cavitation terminology. The first visible manifestation of cavitation occurs on the nose of the test specimen, and thus the term "visible initiation" was applied in this case. Then, succeeding degrees of more fully developed cavitation followed the old progression, regardless of the termination point on the specimen. The following are the definitions of the degrees of cavitation as used in this investigation:

\section{Mercury}

Visible Initiation - continuous ring of cavitation at the throat outlet, about $1 / 8^{\prime \prime}$ long.

Cavitation to Nose - cavitation cloud extends from throat outlet to termination at the nose of the specimen. 

Standard Cavitation - cavitation cloud extends from throat outlet to termination at the middle of the specimen.
Cavitation to Back - cavitation cloud extends from throat out let to termination at the rear of the specimen.

Water
Visible Initiation - cavitation cloud extends from nose of speci- men to a point downstream on specimen about $1 / 8$ " long.
Cavitation to Nose - cavitation cloud extends from nose of speci- men to termination at the middle of the specimen.
Standard Cavitation - cavitation cloud extends from nose of speci- men to termination at the rear of the specimen.

From the pressure profile data in this report, the correspondence between water and mercury from a standpoint of degree of cavitation is as follows:

$\begin{array}{lcl}\text { Mercury Condition } & \text { corresponds to } & \text { Water Condition } \\ \text { Cavitation to Nose } & -- & \text { Visible Initiation } \\ \text { Standard Cavitation } & -- & \text { Cavitation to Nose } \\ \text { Cavitation to Back } & -- & \text { Standard Cavitation }\end{array}$

This would result in the pressure gradients on the surfaces and the termination points on the surfaces being approximately the same for corresponding conditions from water to mercury. 


\section{BIBLIOGRAPHY}

1. M. Kornfeld and L. Suvorov, "On the Destructive Action of Cavitation," J. App1. Phys., Vo1. 15, No. 6 (1944), 495-96.

2. C. F. Naude and A. T. E11is, "On the Mechanism of Cavitation Damage by Nonhemispherical Cavities Collapsing in Contact with a Solid Boundary," J. Basic Engr., Trans. ASME, Series D, Vo1. 83, 1961, pp. 648-656.

3. N. D. Shutler and R. B. Mesler, "A Photographic Study of the Dynamics and Damage Capabilities of Bubbles Collapsing Near Solid Boundaries," J. Basic Engr., Trans. ASME, Series D, Vo1. 87, 1965, pp. 511-517.

4. T. B. Benjamin and A. T. E1lis, "The Collapse of Cavitation Bubbles and the Pressures Thereby Produced Against Solid Boundaries," Royal Society Meeting for Discussion on Deformation of Solids by Impact of Liquids, May 27, 1965, London, England, to be published Proc. Royal Society.

5. L. W. Florscheutz and B. T. Chao, "On the Mechanics of Vapor Bubble Collapse--A Theoretica1 and Experimental Investigation," J. Heat Transfer, Trans. ASME, Series C, Vo1. 87, 1965, pp. 209-220.

6. R. D. Ivany, F. G. Hammitt and T. M. Mitche11, "Cavitation Bubble Collapse Observations in a Venturi," ASME Paper No. 65-WA/FE-20, to be published J. Basic Engr., Trans. ASME.

7. R. D. Ivany and F. G. Hammitt, "Cavitation Bubble Collapse in Viscous, Compressible Liquids--Numerical Analyses," J. Basic Engr., Trans. ASME, Dec., 1965, pp. 977-985.

8. R. Hickling and M. S. Plesset, The Collapse of a Spherical Cavity in a Compressible Liquid, Calif. Inst. Tech. Report No. 85-24, Pasadena, Calif., 1963.

9. F. G. Hammitt, "Observations of Damage in a Flowing System," J. Basic Engr., Trans. ASME, Vo1. 85, Sept., 1963, pp. 347-359.

10. F. G. Hammitt, L. L. Barinka, M. J. Robinson, R. D. Pehlke, and C. A. Siebert, "Initial Phases of Damage to Test Specimens in a Cavitating Venturi as Affected by Fluid and Material Properties and Degree of Cavitation," J. Basic Engr., Trans. ASME, June, 1965, pp. 453-464. 
11. F. G. Hammitt, "Cavitation Damage and Performance Research Facilities," ASME Fluids Engr. Conf., Philadelphia, Pa., May, 1964, Symposium on Cavitation Research Facilities and Techniques, pp. 175-184.

12. M. J. Robinson, "On the Detailed Flow Structure and the Corresponding Damage to Test Specimens in a Cavitating Venturi," Ph.D. Thesis, Nuclear Engineering Department, The University of Michigan, Ann Arbor, August, 1965; A1so 0RA Technical Report No. 03424016-T, Laboratory for Fluid Flow and Heat Transport Phenomena, Nuclear Engineering Department, The University of Michigan, August, 1965.

13. E. Honegger, "Concerning Erosion Experiments". (in German), BBCMitt. Vo1. 14 (1927), pp. 74-95.

14. J. M. Hobbs, "Problems of Predicting Cavitation Erosion from Accelerated Tests," ASME Paper No. 61-HYD-19.

15. S. M. DeCorso, "Erosion Tests of Steam Turbine Blade Materials," ASTM Proceedings, ASTM, Vo1. 64, pp. 782-796.

16. 0. G. Enge1, "Pits in Metals Caused by Collision with Liquid Drops and Soft Metal Spheres," J. of Res. of Nat. Bur. Stds., Vo1. 62, No. 6, Research Paper No. 2958, June, 1959, pp. 229-246.

17. R. W. Kelly, G. M. Wood, R. S. Kulp, and J. V. Altieri, "Cavitation Damage of Mechanical Pump Impellers Operating in Liquid Metal Space Power Loops," CNLM-6101, prepared for NASA by Pratt \& Whitney Aircraft Div., United Aircraft Corp., December 8, 1964.

18. F. G. Hammitt, et. a1., "Cavitation Damage in Mercury and Water in a Cavitating Venturi and Other Components," ORA Technical Report No. 03424-9-T, Laboratory for Fluid Flow and Heat Transport Phenomena, Nuclear Engineering Department, The University of Michigan, Sept., 1963.

19. F. G. Hammitt, M. J. Robinson, C. A. Siebert and F. A. Aydinmakine, "Cavitation Damage Correlations for Various Fluid-Material Combinations," ORA Technical Report No. 03424-14-T, Laboratory for Fluid Flow and Heat Transport Phenomena, Nuclear Engineering Department, The University of Michigan, Oct., 1964.

20. R. T. Knapp, "Recent Investigations of the Mechanics of Cavitation and Cavitation Damage," Trans. ASME, Oct., 1955, pp. 1045-1054.

21. M. S. Plesset, "Pulsing Techniques for Studying Cavitation Erosion of Metals," Corrosion, May, 1962, pp. 181-188.

22. H. G. 01son, unpublished Ph.D. thesis data, Nuclear Engineering Department, The University of Michigan, June, 1966. 
23. M. J. Robinson and F. G. Hammitt, "Cavitation Damage Characteristics in Water and Mercury from Studies in a Cavitating Venturi," ORA Technical Report No. 03424-17-T, Laboratory for Fluid Flow and Heat Transport Phenomena, Nuclear Engineering Department, The University of Michigan, April, 1966.

24. A. T. E11is, "Parameters Affecting Cavitation and Some New Methods for Their Study," Report No. E-115.1, Hydrodynamics Laboratory, C.I.T., October, 1965.

25. F. G. Hammitt, "Damage to Solids Caused by Cavitation," Roya1 Society Discussion, Deformation of Solids Due to Liquid Impact, London, May 27, 1965 (to be published Proc. Royal Soc.).

26. J. M. Mousson, "Pitting Resistance of Metals Under Cavitation Conditions," Trans. ASME, June, 1937, pp. 399-408.

27. H. N. Boetcher, "Failure of Metals Due to Cavitation Under Experimental Conditions," ASME Hydraulics Div. Paper No. HYE-58-1 (Dec., 1935), Trans. ASME, Vo1. 58, 1936, pp. 355-360.

28. G. M. Wood, L. K. Knudsen and F. G. Hammitt, "Cavitation Damage Studies with Rotating Disk in Water," ASME Paper No. 66-FE-11, to be published J. Basic Engr., Trans. ASME.

29. R. Garcia, F. G. Hammitt and R. E. Nystrom, "Comprehensive Cavitation Damage Data for Water and Various Liquid Metals Including Correlations with Material and Fluid Properties," ASTM Symposium on Erosion by Cavitation or Impingement, June 1966, and to be published ASTM Proc. 